\title{
Implication of Genetic Deletion of Wdr13 in Mice: Mild Anxiety, Better Performance in Spatial Memory Task, with Upregulation of Multiple Synaptic Proteins
}

\author{
Shiladitya Mitra *, Ghantasala S. Sameer Kumar, Vivek Tiwari, B. Jyothi Lakshmi, \\ Suman S. Thakur and Satish Kumar*
}

Council of Scientific and Industrial Research - Centre for Cellular and Molecular Biology, Hyderabad, India

\section{OPEN ACCESS}

Edited by:

Christian Henneberger, University of Bonn, Germany

Reviewed by:

Sandra Blaess,

University of Bonn, Germany

Larry Zweifel,

University of Washington, USA

${ }^{*}$ Correspondence:

Shiladitya Mitra

smitra@ccmb.res.in; shiladitya.mitra@gmail.com

Satish Kumar

satishk@ccmb.res.in satishk.scientist@gmail.com

Received: 16 April 2016 Accepted: 08 August 2016 Published: 30 August 2016

Citation:

Mitra S, Sameer Kumar GS, Tiwari V, Lakshmi BJ, Thakur SS and Kumar S (2016) Implication of Genetic Deletion of Wdr13 in Mice: Mild Anxiety, Better Performance in Spatial Memory Task, with Upregulation of Multiple Synaptic

Proteins. Front. Mol. Neurosci. 9:73.

doi: 10.3389/fnmol.2016.00073
WDR13 expresses from the $\mathrm{X}$ chromosome and has a highly conserved coding sequence. There have been multiple associations of WDR13 with memory. However, its detailed function in context of brain and behavior remains unknown. We characterized the behavioral phenotype of 2 month old male mice lacking the homolog of WDR13 gene $\left(W d r 13^{-10}\right)$. Taking cue from analysis of its expression in the brain, we chose hippocampus for molecular studies to delineate its function. Wdr13-10 mice spent less time in the central area of the open field test (OFT) and with the novel object in novel object recognition test (NOR) as compared to the wild-type. However, these mice didn't show any significant changes in total time spent in arms or in frequency of arm entries in elevated plus maze (EPM). In the absence of $W d r 13$, there was a significant upregulation of synaptic proteins, viz., SYN1, RAB3A, CAMK2A etc. accompanied with increased spine density of hippocampal CA1 neurons and better spatial memory in mice as measured by increased time spent in the target quadrant of Morris water maze (MWM) during probe test. Parallel study from our lab has established c-JUN, ER $\alpha / \beta$, and HDAC 1,3,7 as interacting partners of WDR13. WDR13 represses transcription from AP1 (c-JUN responsive) and Estrogen Receptor Element (ERE) promoters. We hypothesized that absence of Wdr13 would result in de-regulated expression of a number of genes including multiple synaptic genes leading to the observed phenotype. Knocking down Wdr13 in Neuro2a cell lines led to increased transcripts of Camk2a and Nrxn2 consistent with in-vivo results. Summarily, our data provides functional evidence for the role of $W d r 13$ in brain.

Keywords: Wdr13, mouse models, synaptic genes, memory, proteomics, behavior

\section{INTRODUCTION}

WDR13 belongs to a class of WD (tryptophan-aspartate) repeat-containing proteins. Human WDR13 gene was discovered and characterized by Singh et al. (2003) and its highly conserved mouse homolog (Wdr13) by Suresh et al. (2005). It was independently discovered in mice by D'Agata et al. (2003) as Cmrg1 (Cerebellar memory related gene 1). Both human and mouse 
homologs of this gene localize on the $\mathrm{X}$ chromosome and encode a protein comprised of 485 amino acids. Western blot analysis shows two major isoforms of WDR13, one near the predicted molecular weight of $53 \mathrm{kDa}$ and another smaller 43 $\mathrm{kDa}$ band corresponding to a truncated 394 amino acid protein (Singh et al., 2015a). WDR13 is a nuclear protein without any consensus nuclear localization signal (Suresh et al., 2005). To elucidate its function, a gene-knockout mouse was generated in our laboratory. The absence of this gene in mice $\left(W d r 13^{-/ 0}\right)$ resulted in age-dependent mild obesity, pancreatic beta cell hyper-proliferation, subsequent hyper-insulinemia (Singh et al., 2012) and improvement of metabolic phenotype in Lepr $(\mathrm{db} / \mathrm{db})$ mice (Singh et al., 2015a).

$W d r 13$ gene is expressed in most tissues with relatively higher expression observed in the brain, pancreas, ovaries, and testes (Suresh et al., 2005). Research from various groups indicates the possible involvement of $W d r 13$ in brain function. D'Agata et al. (2003) implicated its function in learning and memory based on the association between expression of this gene to classical conditioning of rabbit nictitating membrane response. Wdr13 transcript has been shown to be enriched following synaptogenic lesion of the hippocampus in rats, suggesting its role as a possible neuro-protective molecule (Price et al., 2003). WDR13 had also been reported to be associated with the phenotype of hyperactivity, learning and visual-spatial difficulties of an 11-year-old boy having approximately $1.3 \mathrm{Mb}$ duplication at locus Xp11.23p11.3 (El-Hattab et al., 2011).

These reports, however, were based on correlation and did not give any direct evidence of brain specific function of WDR13. In the current work, we have delineated the role of this gene in brain by studying behavioral and molecular changes in $W d r 13$ knockout male mice $\left(W d r 13^{-/ 0}\right)$.

\section{MATERIALS AND METHODS}

\section{Animal Experiments and Handling}

Mice were procured from the central Animal House facility (CCMB). They were housed in polypropylene cages with shredded corn-cob bedding with 12-h light and dark cycle (6 a.m. -6 p.m. light cycle). The required numbers of mice were generated by crossing of wild-type and mutant (heterozygous, $W d r 13^{+/-}$) mice. Unless mentioned specifically, all behavior and molecular data corresponds to male $W d r 13^{-/ 0}$ and wild-type mice in CD1 genetic background. CCMB Institutional Animal Ethics Committee approved all the animal experiments (Reg. No. CPCSEA 20/1999).

\section{Analysis of Brain Metabolism}

Nuclear Magnetic Resonance (NMR) was used to analyze changes in brain metabolites of $W d r 13^{-/ 0}$ and wild-type mice at 10 and 2 months of age. Metabolic measurements of cortex and subcortex were carried out on one group of mice containing wild type and $W d r 13$ knockout mice of age 10 months $(n=5,6)$ by co-infusion of [U-13C6]-Glucose and [2-13C]-Acetate through the tail vein. 13C labeling of amino acids in brain tissue extract was analyzed using $1 \mathrm{H}-[13 \mathrm{C}]$ and 13C-[1H]-NMR spectroscopy. The protocol has been described by previous studies (Patel et al.,
2001; Shameem and Patel, 2012). Two month old $(n=4)$ mice cortex was analyzed for metabolic changes using infusion of [1,6-13C2] Glucose for 10 min using the methodology described earlier (Shameem and Patel, 2012; Tiwari and Patel, 2012).

\section{RNA In situ Hybridization (RISH)}

Dig-labeled RNA probes for anti-sense and sense strands of full length $W d r 13$ cloned in pGMT vector were prepared according to instructions provided by ROCHE. RISH was carried out on cryo sections $(30 \mu \mathrm{M})$ derived from formaldehyde perfused and fixed brain tissue from wild-type and $W d r 13^{-/ 0}$ mice as described previously (Singh et al., 2015b). Images were taken using AxioImager2 (Zeiss) with Apotome.

\section{Behavioral Analysis of Wdr13 ${ }^{-/ 0}$ Mice}

Mice were tested for anxiety, depression, learning and memory. Video tracking software Noldus Ethovision 3.1 was used to record the movements of the mice in the tests. Litter-mates were utilized as control wild-type for different behavioral experiments. $W d r 13^{-/ 0}$ and wild type mice in outbred CD1 background was utilized for all behavioral studies. Few of the following studies were also performed in inbred C57BL/6J background to rule out possibilities of any strain-specific phenotypes.

(i) Open Field Test: This test was designed to study emotionality in rats (Hall, 1934) and later reproduced in mice (Christmas and Maxwell, 1970). This test has since been performed to assess the degree of anxiety and locomoter activity in mice. The Open Field test (OFT) arena is an open square box $50 \times 50 \mathrm{~cm}$. The box is virtually demarcated into a central zone and peripheral zones. The experimental mouse was placed in one corner of the box and allowed to explore the arena for $5 \mathrm{~min}$. The amount of time the mouse spent in the center and periphery zones within 5 min was then noted. Mice with higher anxiety levels tend to spend more time in the periphery and less time in the central area.

(ii) Elevated Plus Maze test: This test too was performed to assess the degree of anxiety in mice (Crawley, 2006). The setup consists of a four armed maze kept on an elevated platform. The maze consists of two open arms and two closed arms (walls on the side). The mouse was kept at the center of the maze facing the open arm and allowed to explore the arena for $5 \mathrm{~min}$. The amount of time spent by the mouse in the open and closed arms was then calculated. The frequency of visit to each arm was also calculated. Mice with higher anxiety levels tend to spend more time in the closed arms and less in the open arms (thigmotaxis).

(iii) Forced Swim Test: Also known as the Porsolt Swim Test (Porsolt et al., 1977), this test is conducted to analyse depression in rodents. In this test the mice were placed in a beaker filled with water till $20-25 \mathrm{~cm}$ and the total duration of immobility was measured. The experiment was videorecorded and analyzed post-recording. Usually a mouse with depression phenotype remains immobile for a longer time (Can et al., 2012). 
(iv) Novel Object Recognition Test: This test had been developed to measure cognition, anxiety and preference for novelty in rodents (Antunes and Biala, 2012). In this experiment, the mice were placed in an open field on the first day. On the second day, two similar objects were introduced in the arena and the mice were habituated to them. On day three, a novel object of different shape and size replaced one of the objects. The discrimination by the mice between two objects was noted (measured as ratio of difference between time spent near novel object and familial object to that of total time spent exploring both objects). Normally, a wild type mouse prefers to explore novel objects.

(v) Hot Plate test: This test is generally used to analyze proper functioning of neuromuscular junction and pain sensitivity (Minett et al., 2012). The mice were placed on a hot plate at $55^{\circ} \mathrm{C}$ and the latency to the first jump was noted.

(vi) Morris water maze (MWM): This experiment was developed for learning and memory analysis in rodents by Morris (1981). There are many variants of the method for training and analysis (Vorhees and Williams, 2006). Here the modified version of the Morris Water Maze (MWM) has been followed. The cues such as a tripod stand, a hanging bucket and specific arrangement of curtains were located outside a tub of $90 \mathrm{~cm}$ in radius and $40 \mathrm{~cm}$ in depth. The mouse was first placed on the submerged platform for $30 \mathrm{~s}$ on the first day and then taken out. In the second trial on day one, the mice were placed in water and then guided to the submerged platform. Usually each mouse were subjected to 2-3 trials in 1 day. The mice in subsequent trials were placed in water and time to reach the platform was noted. If it was unable to reach, it was guided at the end of the trial, which lasted $1 \mathrm{~min} 30 \mathrm{~s}$. At the end of the trial, when the mouse reached the platform, it was left there for $15-30$ s. Latency to reach the platform was noted and this was taken as an indication of learning capacity of the mice. After 5-6 days when the mice learnt to reach the platform placed anywhere in the tub, probe test was conducted $24 \mathrm{~h}$ post last learning trial.

For re-learning experiment, the position of the platform was shifted to a new location after mice learnt to reach in its initial location. The learning ability of the mice to reach the platform in its new location was analyzed over multiple trials.

In the probe test, the platform was removed and the mice were placed in the tub. The time it spends in the quadrant in which the platform was kept was noted. Repeated (extinction) trials were performed $24 \mathrm{~h}$ after the final learning trial. In an extinction trial the mice were subjected to probe trials from random location multiple times. Normally the probability for a wild type to search for the platform decreases over trials (Maei et al., 2009; Terry, 2009).

For long-term memory test, probe trial was not conducted immediately after the learning trial, but mice were subjected to a probe trial after a period of 20 days using the same setup and location of cues. Time spent by the mice in the target quadrant was noted.

\section{Cohorts Used}

Multiple cohorts were used for the afore-mentioned behavioral experiments (Table 1). Multiple experiments were executed in duplicates to validate the phenotype observed. Initially, a cohort of CD1 mice ( $n=5)$ was utilized to perform OFT, Elevated Plus Maze (EPM), Novel Object Recognition test (NOR), and MWM. Between the non-stress experiments of OFT, EPM, NOR and that of MWM, there was an interval of 2 weeks. An independent cohort of CD1 mice $(n=17)$ was then subjected to OFT, EPM, and Forced Swim Test. A separate cohort of mice $(n=9,10 / 8)$ was used to re-perform NOR and Hot Plate test. For MWM, we repeated learning trials and probe test in a separate cohort of mice $(n=6)$. Two other independent cohorts were utilized separately for re-learning experiment and long-term retention test in MWM ( $n=6$ each). We have also repeated FST with a separate cohort of mice ( $n=6$; data not shown).

We used two separate cohorts for performing behavioral tests in C57Bl/6J mice. One cohort of mice $(n=16)$ was tested in OFT. Another $(n=8)$ was used to perform EPM and MWM.

\section{Proteomic Analysis}

Sample preparation, labeling, running of samples in LCMS/MS and analysis were performed as described below. The mass spectrometry proteomics data along with the list of proteins quantified have been deposited to the ProteomeXchange Consortium via the PRIDE partner repository with the dataset identifier PXD002466.

\section{ITRAQ 4 Plex}

We pooled hippocampi from three wild-type and three knockout $\left(W d r 13^{-/ 0}\right)$ mice for the present study. Proteins were extracted from tissue using $0.5 \%$ SDS and were estimated using Bicinchoninic acid assay (BCA) method. Two hundred micrograms of protein from both groups was taken as a starting amount. The protein from each group was treated with $2 \mu \mathrm{L}$ of

\begin{tabular}{lccl}
\hline \multicolumn{2}{l}{ TABLE 1 | List of Cohorts of mice utilized in behavioral experiments. } \\
\hline Strain & Cohort number & $\boldsymbol{n}$ & Behavioral experiments \\
\hline CD1 & 1 & 5 & OFT, EPM, NOR, MWM \\
2 & 17 & OFT, EPM, FST \\
& 3 & $9,10 / 8$ & NOR, Hot Plate Test \\
& 4 & 6 & MWM learning and probe trials \\
& 5 & 6 & MWM relearning trials \\
& 6 & 6 & MWM long term retention \\
& 7 & 6 & FST (data not shown) \\
\hline C57BI/6J & $1^{\prime}$ & 16 & OFT \\
& $2^{\prime}$ & 8 & EPM, MWM
\end{tabular}

$\overline{\text { OFT, Open Field Test; EPM, Elevated Plus Maze; FST, Forced Swim Test; MWM, Morris }}$ Water Maze; NOR, Novel Object Recognition. 
reducing agent [tris (2-carboxyethyl) phosphine (TCEP)] at $60^{\circ} \mathrm{C}$ for $1 \mathrm{~h}$ and the samples were alkylated using $1 \mu \mathrm{L}$ of cysteine blocking reagent, methyl methanethiosulfonate (MMTS) for $10 \mathrm{~min}$ at RT. After alkylation, the samples were digested with trypsin (Sequencing Grade Modified Trypsin, Promega Cat\#:V511A) using $1: 20(\mathrm{w} / \mathrm{w})$ at $37^{\circ} \mathrm{C}$ for $16 \mathrm{hrs}$. We split the samples based on the protein amount $(100 \mu \mathrm{g})$ in each group and labeled with iTRAQ 4plex (catalog \# 4352135, Applied Biosystems, Foster City, CA, USA) reagents as per manufacturer's protocol. In iTRAQ 4-plex experiments, peptides from wild type were labeled with 114 and 115 tags, while knockout samples were labeled with 116 and 117 tags. After labeling, we pooled the samples and carried out desalting using C18 spin columns (89873-Pierce ${ }^{\circledR}$ C18 Spin Columns) as per manufacturer's protocol. Later, the iTRAQ 4-plex labeled samples were processed further for LC-MS/MS analysis.

\section{LC-MS/MS Analysis}

Samples were analyzed on UPLC (Dionex The UltiMate ${ }^{\circledR} 3000$ HPLC) interfaced with Q-Exactive mass spectrometer (Thermo Scientific, Bremen, Germany). Trypsin digested peptides were loaded on a $15 \mathrm{~cm}$ long column (EASY-Spray column ES800, $15 \mathrm{~cm} \times 75 \mu \mathrm{m}$ ID, PepMap C18, $3 \mu \mathrm{m})$. Column was heated at $30^{\circ} \mathrm{C}$ with integrated temperature control. Peptides were separated using linear gradient from 2 to $98 \%$ of buffer B (95\% acetonitrile and $0.1 \%$ formic acid) at a flow rate of $300 \mathrm{nl} / \mathrm{min}$, which was followed by a column re-equilibration reaching $2 \%$ of buffer B for few minutes. Gradient length had been adjusted to $50 \mathrm{~min}$. The acquisition of the data was carried out using Xcalibur 2.1 (Thermo Scientific, Bremen, Germany). MS spectra were acquired in a data dependent manner in the range of $\mathrm{m} / \mathrm{z} 350-1800$ at a scan resolution of 70,000 and followed by top 10 precursor ions selected for MS/MS analysis at a scan resolution of 17,000 . Normalized collision energy (NCE) was set to 27 for fragmentation. The priority of the precursor ion selection was based on the charge state in the order of $2+, 3+$ and $>3+$. Unassigned and single charge state precursor ions were excluded from fragmentation. The dynamic exclusion was set as $30 \mathrm{~s}$ during data acquisition. The nano source was operated with $2.2 \mathrm{KV}$ and the capillary temperature at $300^{\circ} \mathrm{C}$. Isolation width has been adjusted.

\section{Data Analysis}

The acquired data was analyzed using Proteome Discoverer 1.3 (Thermo Scientific, Bremen, Germany) software. We used International Protein Index (IPI) (version 3.83, Mouse) database to search for peptides. The workflow created included spectrum files, spectrum selector and Sequest. Search nodes were given as searches including peptide validator for false discovery analysis and used a reporter ion quantifier for quantitation. We set the parameters, which included Methylthio (C), iTRAQ label at $\mathrm{N}$-terminus of the peptide and lysine as fixed modifications. Oxidation of methionine (M) and deamidation(N/Q) were used as variable modification. The parent and fragment mass error tolerance were set as $20 \mathrm{ppm}$ and $0.2 \mathrm{Da}$ respectively. We acquired a total of 13,059 MS/MS scans. We calculated false discovery rate (FDR) by enabling the peptide sequence analysis using decoy database and top ranked hit based on peptide score, XCorr for Sequest. We applied 1\% FDR in our analysis and proteins with a minimum of 1 unique peptide were considered.

\section{Golgi Cox Staining}

Golgi cox staining was done on $100 \mu \mathrm{M}$ brain sections using a protocol described previously (Chakravarty et al., 2015). Six mice, each of wild-type and $W d r 13^{-/ 0}$ were selected for the analysis. A minimum of six CA1 neurons from hippocampal sections for each mouse was analyzed for spine density. Spines from the apical region of CA1 neurons were considered for the analysis. Spine density was analyzed in dendritic sections of $10 \mu \mathrm{m}$ length. In total, about 90-100 spines were analyzed for each genotype. A semi-automated procedure for calculating spine density was utilized as described previously using FIJI and Image J (Orlowski and Bjarkam, 2012). In brief, highresolution images of spines were converted to 8 bit image using ImageJ and threshold applied. Areas to be analyzed were selected, pasted in a new document and were converted to binary. These were then skeletonized using ImageJ or FIJI and analysis of the skeleton was performed. For analyzing dendritic branching, 6-8 CA1 neurons from five each of wild-type and $W d r 13^{-/ 0}$ mice were traced using NeuronJ plugin and Sholl analysis was performed using Sholl Analysis Plugin (v 1.0) for ImageJ. Images were taken using AxioImager2(Zeiss) with Apotome.

\section{BrDU Labeling and Counting}

Mice were injected with $200 \mathrm{mg} / \mathrm{kg}$ (body weight) of $\mathrm{BrDU}$, $24 \mathrm{~h}$ prior to processing and analysis. BrDU injections were given to mice either in resident conditions or at the final day of learning trials of MWM. Brains were collected while whole body perfusion. Serial coronal sections of $30 \mu \mathrm{m}$ each were obtained from a single brain encompassing SVZ (Subventricular Zone) and SGZ (Sub Granular Zone) or DG (Dentate Gyrus) and every 6th section (excluding the early and late formations) were processed for immunohistochemistry using a protocol described previously (Becker et al., 2008). Similar sections from $W d r 13^{-/ 0}$ and wild-type were stained for BrDU incorporation[Anti-BrDU (Sigma, B8434) 1:300] by fluorescent labeling or DAB (Invitrogen) staining according to a previously described protocol (Singh et al., 2012, 2015b) or manufacturer's instructions and counting of one hemisphere was carried out. Area of each DG per section was analyzed using ImageJ and $\mathrm{BrDU}$ counts were normalized for the median areas of the sections (DG). A minimum of 5 mice and $6 \mathrm{~s}$ from each mouse has been used for the experiment.

\section{Cell Culture and Transfections}

Neuro2a cells were cultured in DMEM media with 10\% Fetal Bovine Serum supplemented with antibiotics. Neuro2a cells grown in 24 well plates were assayed for effect of WDR13 on the expression of luciferase from AP1 and ERE site containing promoters using protocol previously described (Singh et al., 2015b). For analysis of luciferase from AP1 site containing 
promoter, Flag-WDR13 was co-transfected with c-JUN at (150:150) ng and (200:150) ng along with AP1-Luciferase and in Neuro2a cells in 24 well plate. For analysis of luciferase from ERE site containing promoter, Flag-WDR13 was transfected at $150 \mathrm{ng}$ along with ERE-luciferase and in Neuro2a cells grown in 24 well plate, with or without supplementation of $10 \mathrm{nM}$ Estradiol. Neuro2a cells used for assaying luciferase activity from ERE-promoter were maintained in DMEM media with $10 \%$ charcoal stripped serum. Transfection was carried out using Lipofectamine LTX (Life Technologies) as per manufacturer instructions. The results obtained from luciferase activity were normalized to $\beta$-galactosidase activity (indicative of transfection efficiency). Wdr13 siRNA (Sc-155258-Santacruz) and control scrambled RNA (Sc-37007) (Santacruz) were introduced in Neuro2a cell line using RNAiMax (Invitrogen) at $100 \mathrm{nM}$ as per manufacturer's instructions and previous reports (Singh et al., 2012). All the experiments were conducted in triplicates.

\section{RNA Isolation, Primer Designing, and Real Time Analysis}

The primers were designed using the Primer3 software and PrimerBank. RNA was isolated using Trizol $^{\mathrm{TM}}$ method and cDNAs were prepared using the protocol described by Sambrook and Russell (2001), and other previous studies (Singh et al., 2012, 2015b). Briefly, hippocampi were homogenized in Trizol ${ }^{\mathrm{TM}}$ and 1/10th volume of 1-Bromo 3-Chloropropane (Sigma) added to the solution. Aqueous phase was collected after centrifugation and RNA precipitated using equal volumes of isopropanol. After ethanol wash, RNA was air-dried and dissolved in DEPC treated water. Real time PCR was performed using SYBR green $2 \mathrm{X}$ mix (Invitrogen and Thermo-Fischer). ABI Prism SDS 7000 and ABI 3900 HT were used to perform real time PCR as per company protocol.

Primer sequences:

\begin{tabular}{lll}
\hline $\begin{array}{l}\text { Gene } \\
\text { name }\end{array}$ & Forward $\left(\mathbf{5}^{\prime} \mathbf{-} \mathbf{3}^{\prime}\right)$ & Reverse $\left(\mathbf{3}^{\prime} \mathbf{-} \mathbf{5}^{\prime} \mathbf{)}\right.$ \\
\hline Camk2a & TGCCTGGTGTTGCTAACCC & CCATTAACTGAACGCTGGAACT \\
Gria1 & TCCCCAACAATATCCAGATAGGG & AAGCCGCATGTCCTGTGATT \\
Gria2 & GCCGAGGCGAAACGAATGA & CACTCTCGATGCCATATACGTTG \\
Grin1 & AGAGCCCGACCCTAAAAAGAA & CCCTCCTCCCTCTCAATAGC \\
Grin2a & ACGTGACAGAACGCGAACT & TCAGTGCGGTCATCAATAACG \\
Nrgn & CAAACCCCATACTCCCAAAA & ACGAAAGGACTGGTGGTTG \\
Nrxn2 & GCTCTGCATCCTCATTCTCC & TGTTCTCTTGGCCTTGCT \\
Rab3a & GTGGGCAAAACCTCGTTCCT & TCCTCTTGTCGTTGCGGTAGA \\
Syn1 & AGCTCAACAAATCCCAGTCTCT & CGGATGGTCTCAGCTTTCAC \\
\hline
\end{tabular}

\section{Western Analysis}

Protein was isolated from hippocampi after homogenizing the tissues in SDS lysis buffer (Sambrook and Russell, 2001). Western Blotting was performed using manufacturers protocol or protocol previously described (Singh et al., 2012, 2015b) with antibody against WDR13 [(HPA000913, Sigma) 1:1000 in 5\%BSA], c-JUN [(sc-45, Santacruz) $1: 500$ in 5\%BSA] and $\beta$-ACTIN [(sc-47778, Santacruz) 1:1000 in 5\%BSA].

\section{Histological Analysis}

We performed Nissl staining and Hematoxylin and Eosin (H\&E) staining on brain cryo-sections $(30 \mu \mathrm{m})$ of 4 month old wild-type and $W d r 13^{-/ 0}$ mice to understand any gross changes in anatomy. For H\&E staining (Fischer et al., 2008), the sections were airdried and then immersed in Hematoxylin solution followed by Eosin solution with washes in water. The sections were then dehydrated using a gradient of alcohol concentrations, washed in xylene and mounted. For Nissl staining (Nissl, 1894), air-dried cryo-sections were de-fatted using xylene and absolute alcohol before rehydrating them and immersing in $0.1 \%$ Cresyl Violet solution (containing glacial acetic acid). The sections were then washed in water, dehydrated and mounted on slides.

\section{Statistical Analysis}

One or Two way analysis of variance (ANOVA) and student's unpaired $T$-test were conducted with significance at $p<0.05$ (denoted as $*^{*}$ ) and at $p<0.005$ (denoted as ${ }^{* *}$ ). For samples with $n>5$, data are presented as mean \pm SEM.

\section{RESULTS}

Our objective was to delineate the distribution of WDR13 in the brain. Both the isoforms of WDR13-53 and $43 \mathrm{kDa}$, showed differential expression in 2 months old mice with Cerebellum (Cr) showing comparatively higher levels of expression, followed by other regions of the brain, namely, Hipocampus (Hip), Cortex $(\mathrm{Cx})$, and Olfactory bud (Ob) (Figure 1A). Hypothalamus (Hypo) showed lower expression levels as compared to Cerebellum. Previous reports (D'Agata et al., 2003) and, those reported in Allen Institute of Science Mouse Brain Atlas (Lein et al., 2007) showed that $W d r 13$ transcript prominently localized to Cortex, Hippocampus, Cerebellum, and Olfactory Bulb. We performed RNA in-situ hybridization (RISH) using antisense probe against full length $W d r 13$ and found similar results (Figure 1B, Supplementary Figure 1). Considering its expression and previous reports of its association with memory (D’Agata et al., 2003), we selected hippocampus for our subsequent analysis.

We also compared whole brains from wild-type and $W d r 13^{-/ 0}$ mice to investigate any notable differences. Analysis of the brains did not reveal any significant differences in weight (Singh et al., 2012) or shape. We also did not find any significant differences $(n=3)$ in the gross anatomy of the brains (in both coronal and sagittal sections) from wild-type and $W d r 13^{-/ 0}$ mice (Supplementary Figure 2).

\section{Two Months Old Wdr13-/0 Mice Did Not Show Changes in Brain Metabolism}

$W d r 13^{-/ 0}$ mice exhibited changes in general metabolism with progression of age (Singh et al., 2012), which became prominent at an age of 9 months. We performed NMR analysis of brain metabolites in 2 months $(n=4)$ and 10 months age $(n=5,6)$ to find out if there were any changes in brain metabolism, and 
A (i)

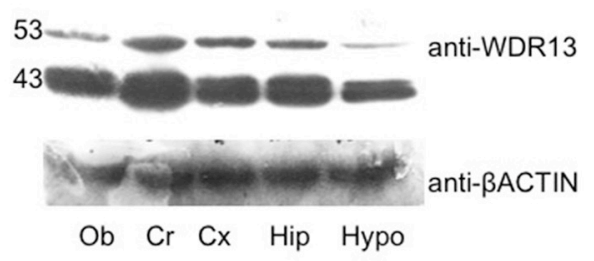

B (i)

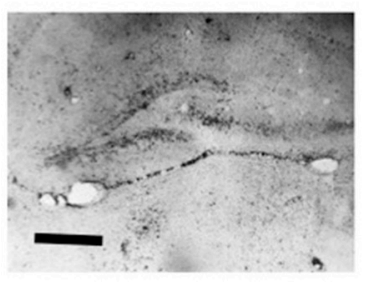

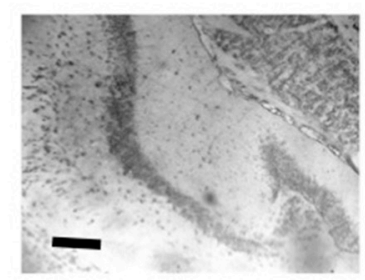

Wdr13 antisense
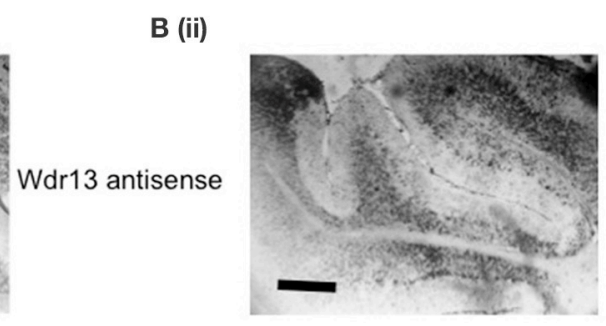

Wdr13 sense

B (ii)

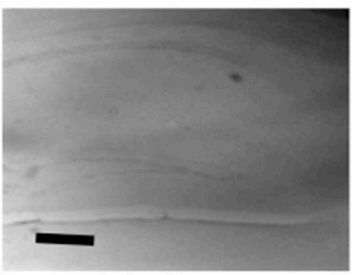

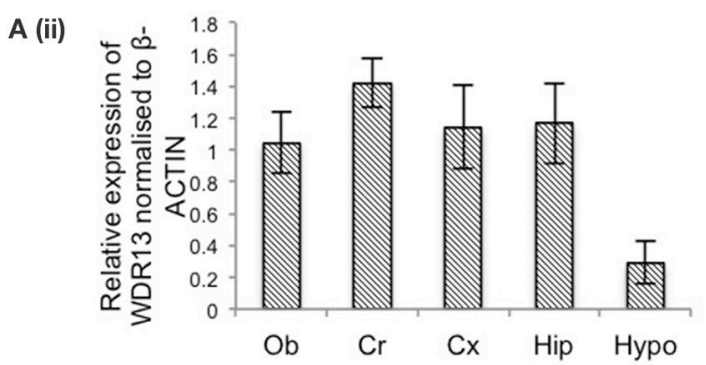

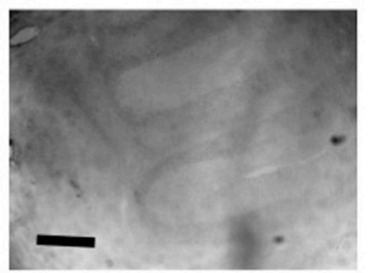

FIGURE 1 | (Ai) Representative blot for western analysis using antibody against WDR13 in different regions of the mice brain at 2 months age (Ob, Olfactory bulb; Cr, Cerebellum; Cx, Cortex; hip, Hippocampus; Hypo, Hypothalamus). (Aii) Relative quantification of expression of WDR13 in different brain regions ( $n=3$ ). Data represented as $\pm S D$ (B). RNA-in situ hybridization using full length anti-Wdr13 probe showing localization in (i) Hippocampus and (ii) Cerebellum. Top panel(s) depicts sections probed using Wdr13 antisense probe and bottom panel(s) depict sections probed using Wdr13 sense probe. Scale: $100 \mu \mathrm{m}$.

if these were correlated to changes in systemic metabolism in $W d r 13^{-/ 0}$ mice.

We found no significant changes in cortical brain metabolism in 2 months old $W d r 13^{-/ 0}$ mice (Figures 2A,B). However, there was a significant increase in $13 \mathrm{C}$ concentration of glutamate (Glu) from [U-13C6]Glucose $(p<0.05)$ but not in the levels of metabolites of cortex and subcortex of $W d r 13^{-/ 0}$ mice at 10 months of age (Figures 2C-F). There were also no significant changes $(p>0.05)$ in the 13C glutamate levels enriched from [2-13C]-Acetate (Figures 2G,H) at this age.

Glucose is utilized by both neurons and astroglia in the brain for their metabolism, whereas acetate is specifically taken up and assimilated by astrocytes (Waniewski and Martin, 1998). Labeling of Glutamate, GABA and Glutamine from [U13C6]Glucose indicates initial estimate of the glutamatergic, GABAergic TCA cycle and total neurotransmitter cycle fluxes, respectively. Labeling of Glutamate, GABA and Glutamine from [2-13C]Acetate is representative of astroglial metabolism (Shameem and Patel, 2012). Thus, the increase in glutamate metabolism enriched from glucose but not acetate indicated it to be specific to neurons. Hence, the observed results might be primarily because of neuron specific activity of $W d r 13$. However, since brain metabolism is altered by changes in levels of circulating insulin (Bingham et al., 2002) and in obesity (Yau et al., 2012), studying $W d r 13^{-/ 0}$ mice at 10 months might not distinguish properly between the brain-specific function of $W d r 13$ and changes in systemic metabolism. Therefore, to understand the primary brain and behavior phenotype of $W d r 13^{-/ 0}$ mice, all behavioral, molecular and histological studies were carried out at 2-3 months of age.

Based on existing literature and the pattern of expression of $W d r 13$ in the brain, we analyzed $W d r 13^{-/ 0}$ mice for any altered anxiety or cognitive function (s).

\section{Wdr13 ${ }^{-/ 0}$ Mice Showed Mild Anxiety}

$W d r 13^{-/ 0}$ mice in both CD1 (Figures 3A,B; $p<0.05 ; n=$ 17; Cohort 2 and Supplementary Figure 3A; $p=0.07 ; n=$ 5; Cohort 1) and C57Bl/6J (Figures 5Ai,ii; $p<0.05 ; n=16$; Cohort $1^{\prime}$ ) genetic background spent less time in the central area and traversed more distance in the OFT indicating anxiety and hyper-activity. There were no significant differences in pain response (Figure $3 C ; p=0.26)$ in hot plate test $(n=$ 


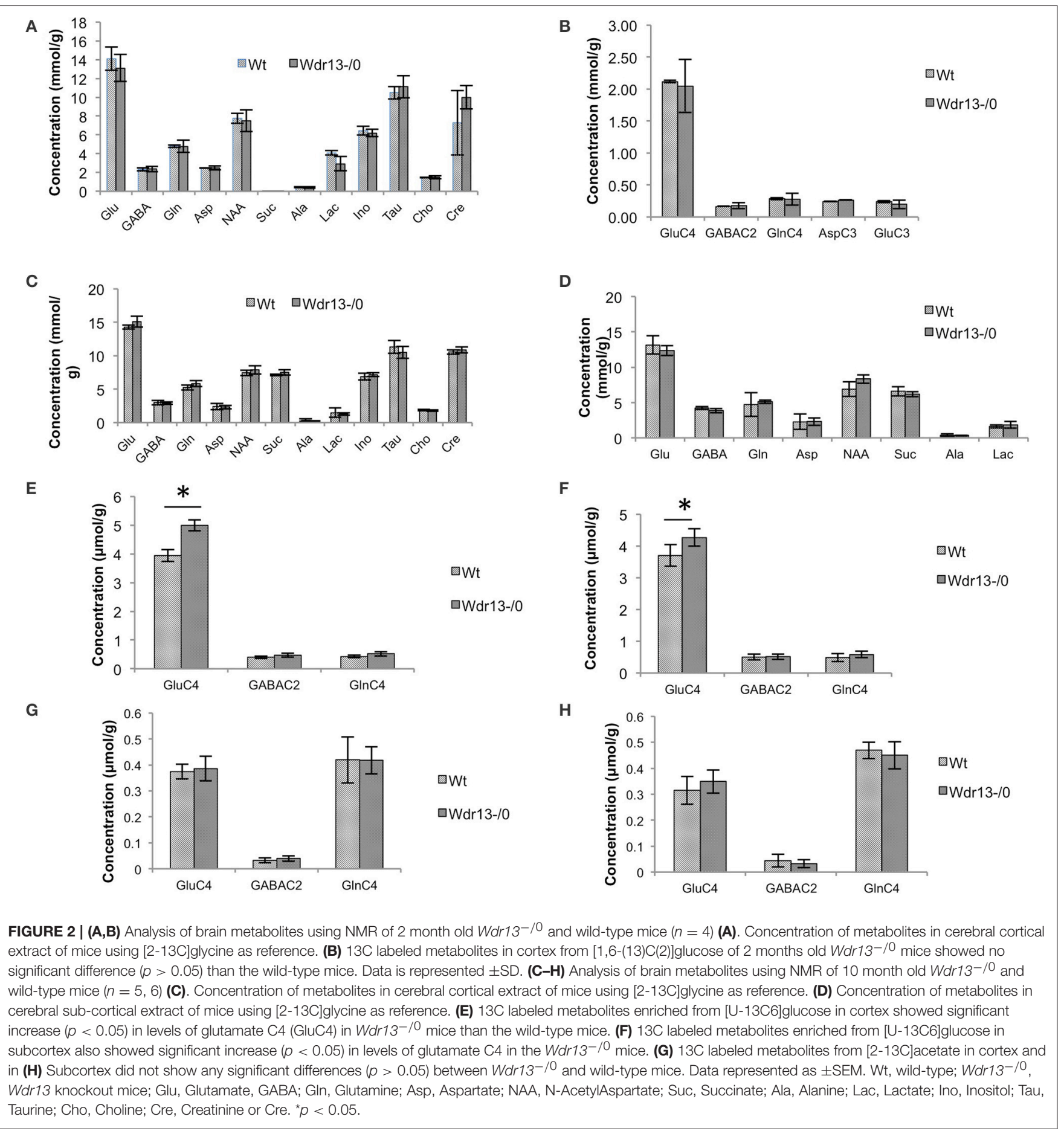

8; Cohort 3), indicating that neuro-muscular junctions and motor response were not affected. In the NOR, $W d r 13^{-/ 0}$ mice spent less time (Figure 3D, $p<0.05 n=10$, 9; Cohort 3 and Supplementary Figure 3B; $p=0.06 ; n=5$; Cohort 1 ) in Discrimination Index (DI) exploring the novel object and more time with the familiar object. In other words, the $W d r 13^{-/ 0}$ mice actively discriminated against the novel object. Hence this behavioral phenotype may be associated with novelty driven anxiety, rather than the lack of ability to discriminate as the DI $\neq 0$. The mutant mice however, didn't show any significant changes in total time spent and frequency of visit to arms in EPM (Figures 3E,F; $n=17$; Cohort 2 and Supplementary Figure 3C; $n=5$; Cohort $1 ; p>0.05)$, although in $\mathrm{C} 57 \mathrm{Bl} / 6 \mathrm{~J}$ background $\left(n=8\right.$; Cohort $\left.2^{\prime}\right)$, they showed a slight $(p=0.06)$ increase in frequency of visit to the closed arm [Figures 5Bi,ii]. In forced swim test (FST), the $W d r 13^{-/ 0}$ mice $(n=17$; Cohort 


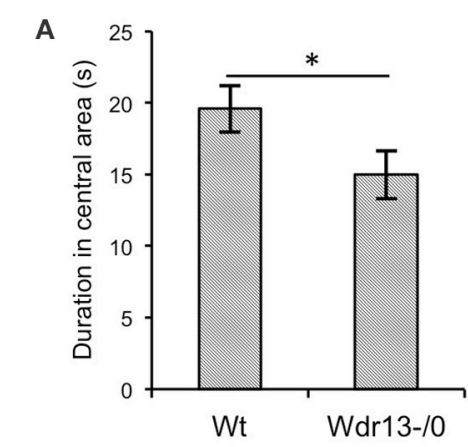

D

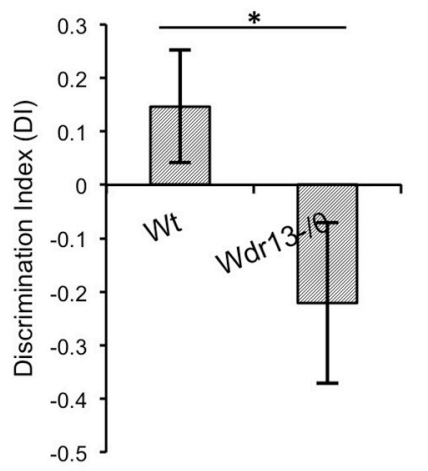

B

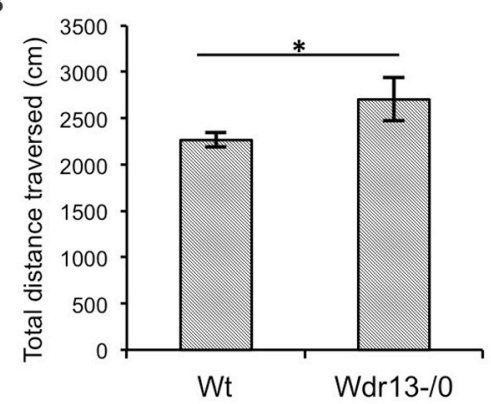

C

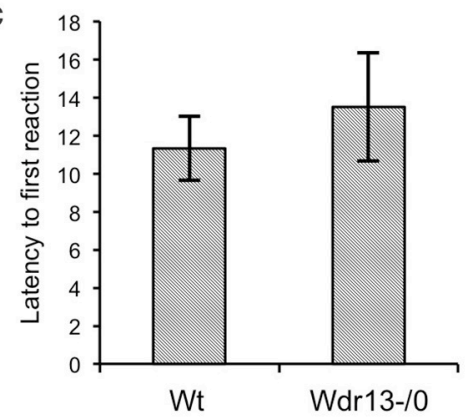

E

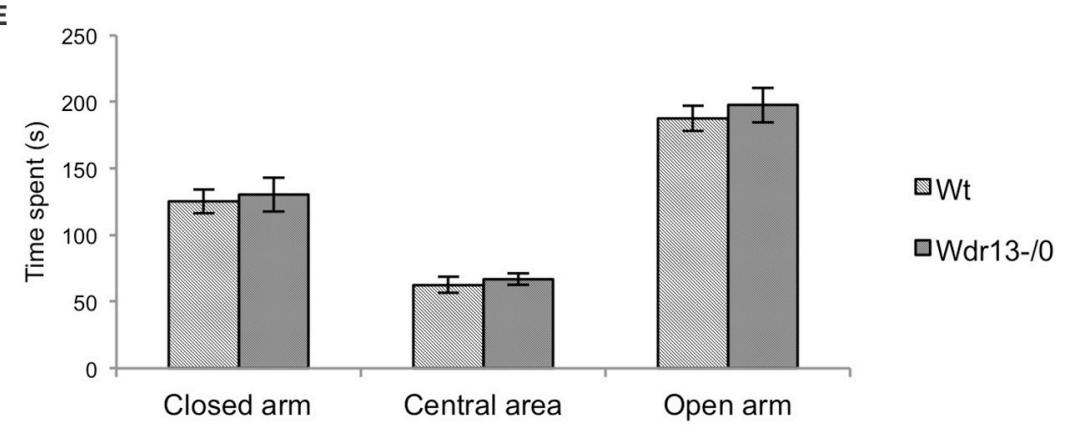

F

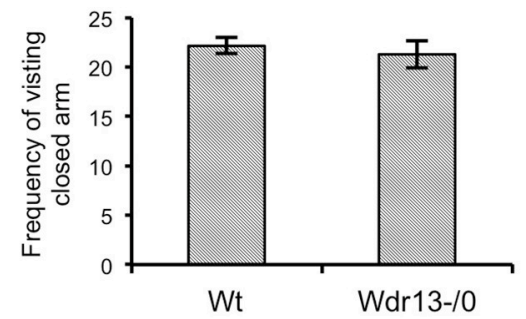

G

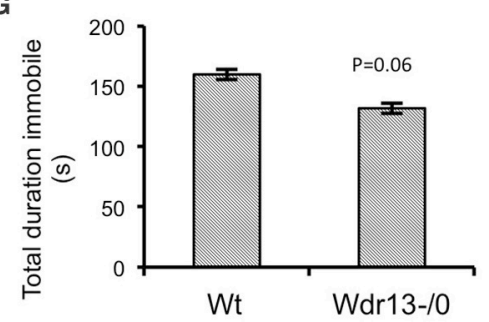

FIGURE 3 | Behavioral analysis of $\mathbf{W d r 1 3 ^ { - / 0 }}$ and wild-type mice at $\mathbf{2}$ months of age. (A) Time spent in the central area of open field test. Wdr13 ${ }^{-/ 0}$ mice spent significantly ( $T$-test; $p<0.05$ ) less time in the central area of the open field than wild-type mice $(n=17$; Cohort 2). (B) Total distance traversed in open field test. Wdr13-/0 mice traveled significantly ( $T$-test; $p<0.05)$ more distance in the open field arena than wild-type mice $(n=17$; Cohort 2$)$. (C) Hot plate test. There was no significant difference between $W d r 13^{-/ 0}$ and wild-type mice ( $T$-test; $\left.p>0.05\right)$ in latency to react to pain sensing when placed on a hot plate $\left(55^{\circ} \mathrm{C}\right)(n=8$; Cohort 3$)$. (D) Novel object recognition test. There was a significant difference ( $T$-test; $p<0.05)$ between $W d r 13^{-} / 0$ mice and the wild-type mice in discrimination index $(n=10$, 9; Cohort 3). The knockout mice spent less duration exploring the novel object as compared to the wild type. (E,F) Elevated plus maze test. Wdr13-/0 mice did not show any significant differences ( $T$-test; $p>0.05)$ than the wild-type mice in total time spent and frequency of visit to closed arms of the elevated plus maze $(n=17$; Cohort 2) (G). Forced swim test. Wdr13-/0 mice showed slightly less immobility as compared to the wild-type mice ( $n=17$; Cohort 2). This difference was however not statistically significant (T-test; $p=0.06)$. Data represented as \pm SEM. Wt, wild-type; $W d r 13^{-/ 0}$, Wdr13 knockout mice. ${ }^{*} p<0.05$.

2 and Cohort 7) showed slightly lesser immobility (Figure 3G; $p=0.06)$ as compared to wild-type, though this was not statistically significant. All these data collectively indicated that the $W d r 13^{-/ 0}$ mice exhibited mild anxiety.

\section{Wdr13-/0 Mice Showed Better Performance in Hippocampal Dependent Spatial Memory Task Associated with Upregulated Synaptic Proteins}

Hippocampus has been shown to be involved in spatial learning and spatial memory (Vorhees and Williams, 2006; Clark et al., 2007; Inostroza et al., 2011; Barnhart et al., 2015) and also long term retention of memory (Ramos, 2000) as assessed by MWM. Hence we employed MWM as a test to assess hippocampal dependent learning and memory behavior (Figure 4A).

$W d r 13^{-/ 0}$ mice showed no significant difference $(p>0.05)$ in the time taken to reach the platform through the learning trials [Figure 4B (CD1; $n=6$; Cohort 4)]. Using another cohort of mice we performed re-learning experiment, when the platform was re-located after the mice were trained to reach the platform in a specific quadrant. In this experiment also $W d r 13^{-/ 0}$ mice $(n=6$; Cohort 5$)$ didn't differ significantly $(p>0.05)$ from the wild-type in the time taken to reach the platform in the new location (Figure 4C). However, $W d r 13^{-/ 0}$ mice spent more time in the target quadrant during the probe (extinction) trials 


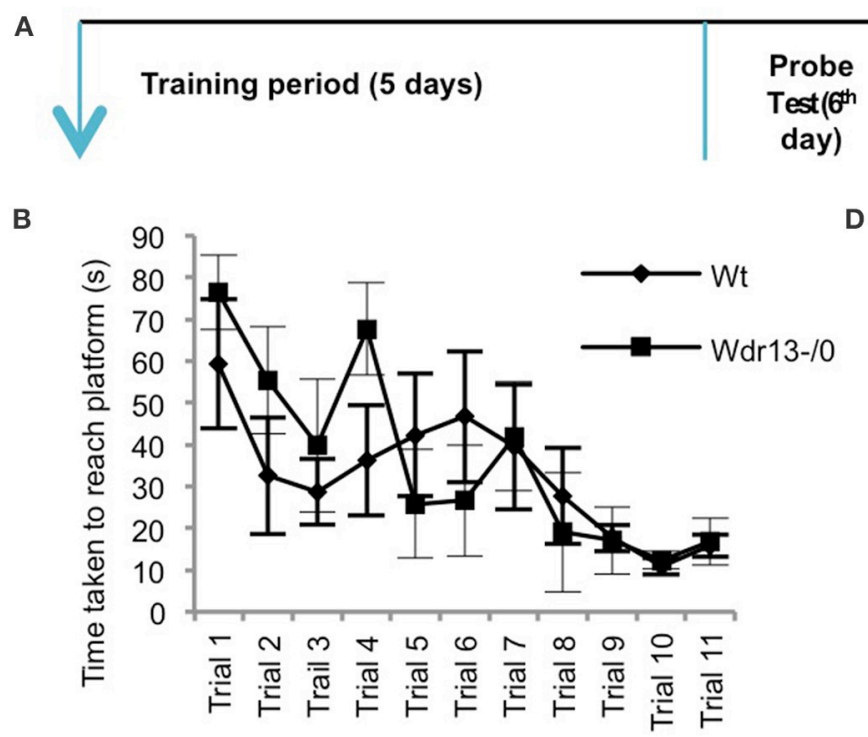

Retention (20 days)
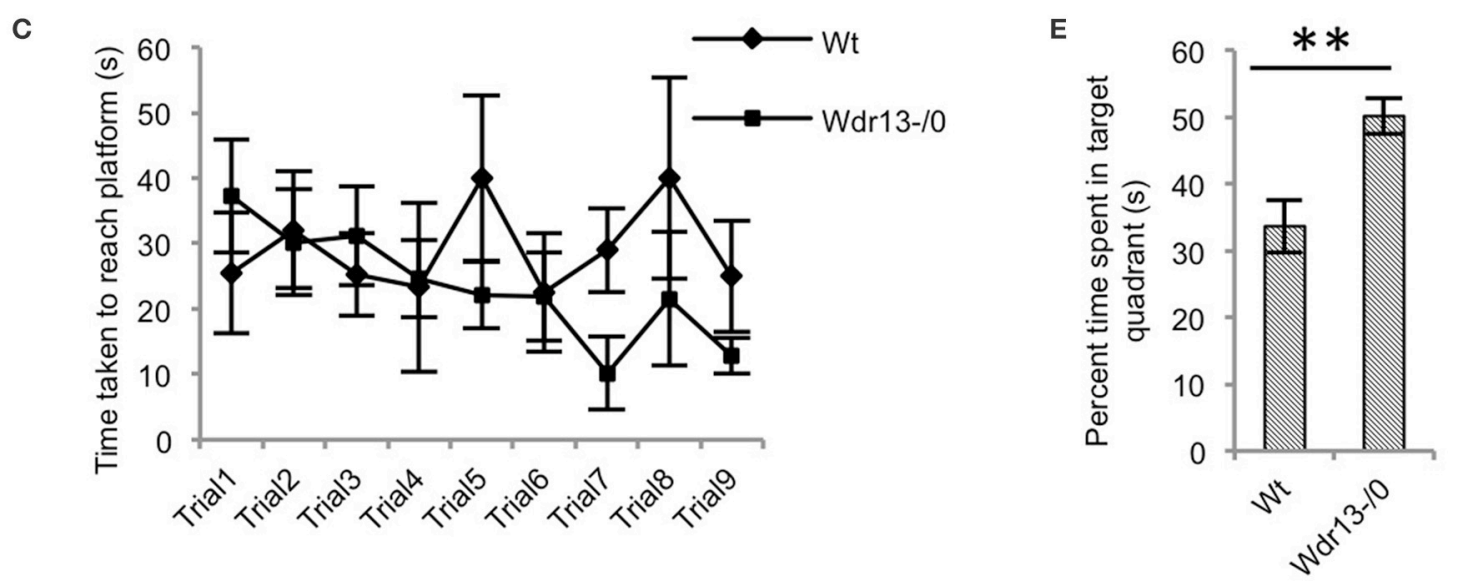

FIGURE 4 | The Morris water learning and memory test. (A) Schematic of the protocol followed for the experiments. (B) There was no significant difference (ANOVA; $p>0.05$ ) between Wdr13-10 and the wild-type mice in the latency (time) to reach the platform through the learning trials $(n=6$; Cohort 4). (C) Re-learning experiment showed no significant difference (ANOVA; $p>0.05$ ) between the Wdr13-/0 and wild-type mice ( $n=6$; Cohort 5). (D) On successive (extinction) probe trials, $W d r 13^{-/ 0}$ mice spent significantly [ANOVA, $\left.F_{(1,40)}=14.24 ; p<0.005\right]$ more time in the target quadrant as compared to the wild-type mice $(n=6$; Cohort 4). (E) $W d r 13^{-/ 0}$ mice showed better long-term memory by spending significantly $(T$-test; $p<0.005)$ more time in the target quadrant when subjected to probe trial after 20 days of learning phase $\left(n=6\right.$; Cohort 6). Data represented as \pm SEM. Wt, wild-type; Wdr13 ${ }^{-/ 0}$, Wdr13 knockout mice. ${ }^{\star} p<0.05,{ }^{* \star} p<0.005$.

$\left\{\left[\right.\right.$ Figure 4D; ANOVA, $\left.F_{(1,40)}=14.24 ; p<0.005\right](\mathrm{CD} 1 ; n=$ 6; Cohort 4)\}, which were performed on the same cohort of mice which underwent learning trials. Probe trial after learning trials was also conducted on a separate cohort of mice and similar results [Supplementary Figure 3D; ANOVA, $F_{(1.56)}=$ 5.44; $n=5$; Cohort $1 ; p<0.05$ ] were obtained, validating the observed phenotype. Interestingly, even in a long term retention test performed 20 days after learning trials on an independent cohort of mice, the mutant ( $n=6$; Cohort 6) spent significantly more time (Figure 4E; $p=0.003$ ) in the target quadrant. We found similar results using $W d r 13^{-/ 0}$ and wild-type mice in C57Bl/6J inbred background; mutant mice did not show any significant differences in the latency to reach the platform during the learning trials [Figure 5Ci (C57Bl/6J; $n=8$; Cohort $\left.2^{\prime}\right)$ ] but spent more time in the target quadrant $\{$ [Figure 5Cii; ANOVA, $\left.F_{(1,36)}=10.24 ; p<0.005\right]\left(\mathrm{C} 57 \mathrm{Bl} / 6 \mathrm{~J} ; n=8\right.$; Cohort $\left.\left.2^{\prime}\right)\right\}$ during the extinction probe trials. Thus, MWM test indicated that the $W d r 13^{-/ 0}$ mice didn't show any differences in learning ability, but had improved retention of spatial memory in MWM than the wild-type and this phenotype was strain independent.

Singh et al. (2012) had previously shown that in $W d r 13^{-/ 0}$ mice, there was an increase in pancreatic beta cell proliferation. We asked whether in the brain of the mutant mice, the proliferation of adult neuronal precursor cells were affected. Since, adult neurogenesis has been implicated in learning and memory (Deng et al., 2010), we also asked if the enhanced spatial memory phenotype of $W d r 13^{-/ 0}$ mice was associated with increased neuronal proliferation induced adult 


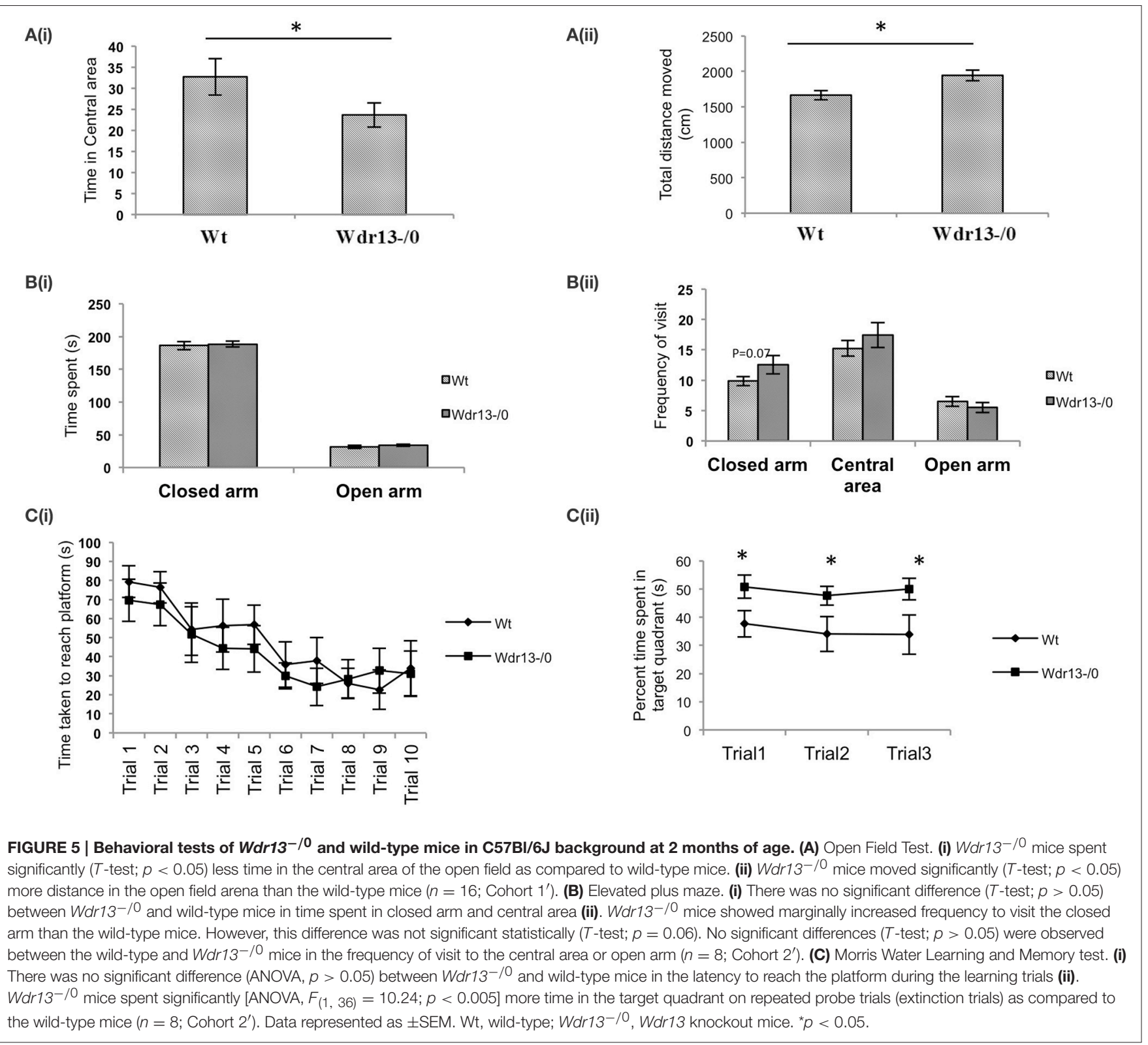

neurogenesis. However, BrDU labeling of proliferating neurons in the Sub Ventricular Zone (SVZ) and Dentate Gyrus (DG) of Sub Granular Zone (SGZ) of $W d r 13^{-/ 0}$ and wild-type mice under resident conditions showed no significant changes (Supplementary Figures $4 \mathbf{A}, \mathbf{A}^{\prime}, \mathbf{B}, \mathbf{B}^{\prime} ; p>0.05$ ). Next, we wanted to know whether absence of $W d r 13$ had any effect on eural proliferation after the mice was subjected to learning tasks. Since learning tasks are shown to increase neurogenesis (Gould et al., 1999), we checked BrDU incorporation in proliferating neurons after MWM learning trials but again failed to note significant changes (Supplementary Figures 4C,D; $p>0.05$ ). It may be noted that we also did not find significant difference of labeled BrDU cells between wild-type controls and those subjected to learning task. This is not a contradiction because Gould et al.
(1999) also stated that the increased neurogenesis that they observed was mainly due to stability of neural progenitors labeled with BrDU before the start of the learning trials. The authors also failed to find any changes in number of cells labeled during or after the trials, which was similar to our findings. This indicated that adult neurogenesis might not have any significant role behind the observed phenotype.

Dendritic spines have been associated with synaptic plasticity (Segal, 2005) and spine density and structures have been implicated with long and short term memory (Moser et al., 1994; Leuner et al., 2003; Restivo et al., 2009). Therefore, we analyzed spine density of apical CA1 hippocampal neurons from wildtype and mutant mice. We found that it was significantly higher $(14 \% ; p<0.05)$ in the $W d r 13^{-/ 0}$ mice as compared to the 


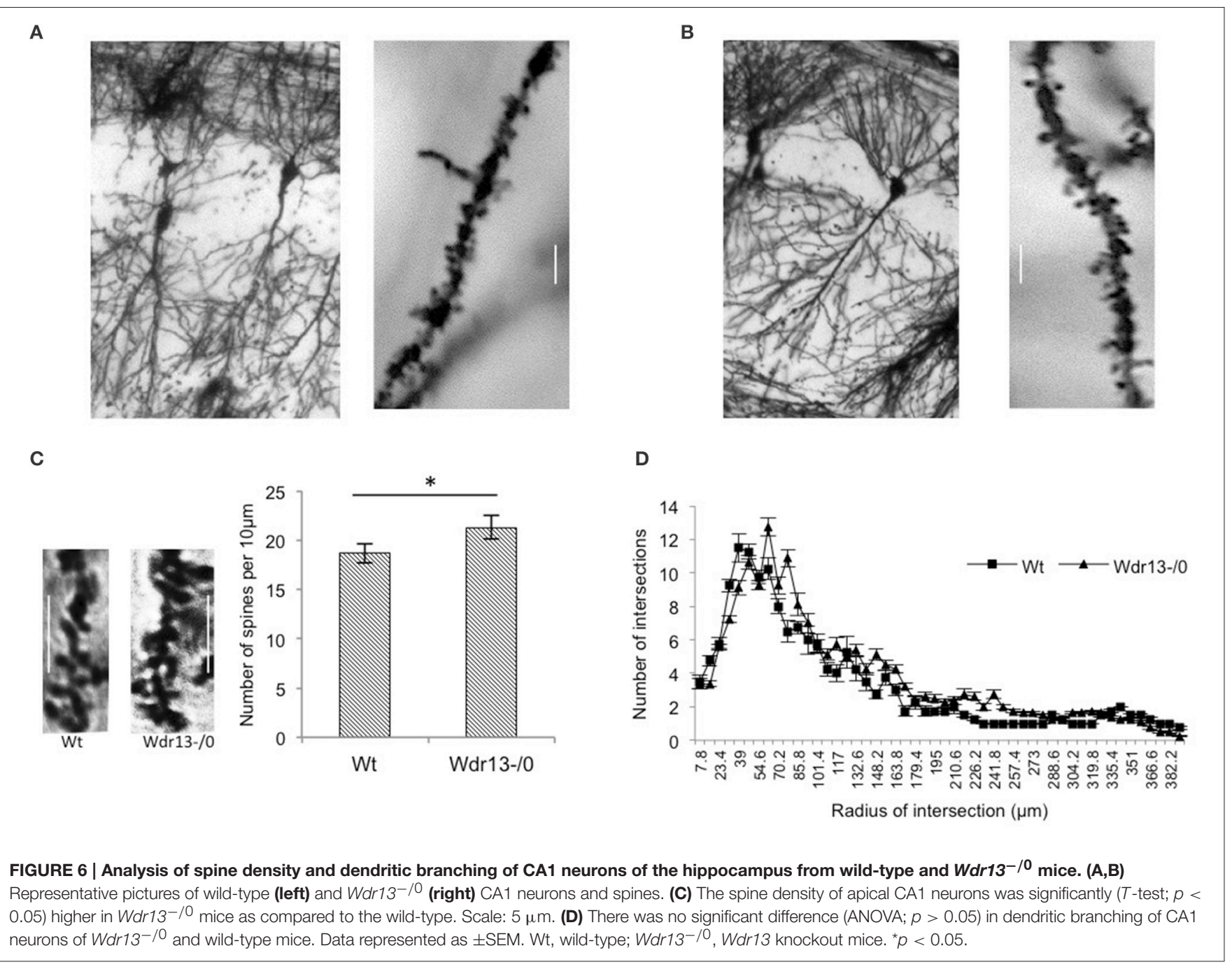

wild-type (Figures 6A-C). We also analyzed dendritic branching of hippocampal CA1 neurons which revealed no significant differences (Figure 6D; ANOVA, $p>0.05$ ) between the wild-type and $W d r 13^{-/ 0}$ mice.

To understand the molecular mechanism(s) behind the observed phenotype, iTRAQ based quantitative proteomics was done from hippocampus of $W d r 13^{-/ 0}$ and wild-type mice. Proteomic analysis (Supplementary Sheet 1; Table 2) revealed that 78 proteins were upregulated at greater than 1.5 folds out of a total of 170 quantified ( $1 \%$ FDR) proteins in the $W d r 13^{-/ 0}$ mice. These upregulated proteins included synaptic proteins, namely, SYN1, RAB3A, CAMK2A, and SV2B, proteins belonging to the 14-3-3 family, tubulins, dynamins, etc. In a separate proteomics experiment (data not shown), we found a decrease in protein levels of neurogranin (NRGN) in $W d r 13^{-/ 0}$ hippocampus.

Transcription analysis of Syn1 (synapsin1) and Rab3a (Figure 7A) from hippocampus was consistent with the proteomics data $(p<0.05)$, implying that absence of $W d r 13$ gene resulted in upregulation of key synaptic genes in mice. Similarly, Nrgn transcription was downregulated $(p=0.03)$. There were, however, no significant changes in the transcript levels of Grin1, Grin2a (NMDA receptors) and Gria1, Gria2 (AMPA receptors) but changes $(p<0.05)$ were observed in transcript levels of Camk2a consistent with the proteomics data (Figure 7B). Interestingly, we also found a significant upregulation in transcript levels of immediate early genes c-Fos and Arc, but not $B d n f$ (Supplementary Figure 5) in hippocampus of $W d r 13^{-/ 0}$ mice when subjected to a novel context (objects placed in an open field) as compared to the wild-type mice.

We wanted to understand whether the changes observed in the expression of multiple synaptic genes were due to the genetic deletion of $W d r 13$. We found that downregulation of $W d r 13$ in Neuro2a cells (Supplementary Figures 6A,C) resulted in upregulation of Camk2a and Nrxn2 (Figure 7C), indicating direct effect of absence/levels of WDR13 on the expression of these genes. Previous work carried out in our laboratory has established $\mathrm{cJUN}, \mathrm{ER} \alpha / \beta$, PHIP, and HDACs as interacting partners of WDR13 (V. P. Singh and Shalu Singh, personal communication). We found that in Neuro2a cell line, WDR13 caused repression in transcription $(p=0.03)$ 
TABLE 2 | Proteins found up-regulated (>1.5 folds) in the hippocampus of $W d r 13^{-/ 0}$ mice as compared to wild-type mice (78 out of 170 quantified).

\begin{tabular}{lll}
\hline No. Category & Proteins upregulated \\
\hline $1 \quad$ Unknown & 19 (IPI00831115.3, IPI01027830.1, IPI00986691.1, IPI00753044.1, IPI00775970.1, IPI00974916.1, \\
& IPI00473320.2, IPI00649084.1, IPI00990529.1, IPI00110658.1, IPI00831369.1, IPI00475306.1, IPI00987992.1, \\
& IPI01026987.1, IPI00648119.1, IPI00762803.1, IPI00265107.4, IPI00830929.1, IPI00970521.1)
\end{tabular}

\begin{tabular}{lll}
\hline & Synaptic transmission, synaptic \\
vesicle cycling, synapse molecule & 16
\end{tabular}
pathway

\begin{tabular}{|c|c|c|}
\hline $2 \mathrm{~A}$ & AMPA cycling & 2 (Vesicle-fusing ATPase, Alpha-soluble NSF attachment protein) \\
\hline 2B & Glutamate cycling & $\begin{array}{l}3 \text { (Vesicular glutamate transporter 1, Isoform Glt-1B of Excitatory amino acid transporter 2, Calcium-binding } \\
\text { mitochondrial carrier protein Aralar1) }\end{array}$ \\
\hline $2 \mathrm{C}$ & GABA metabolism & 1 (Isoform 2 of 4-aminobutyrate aminotransferase, mitochondrial) \\
\hline 2D & Cam kinase regulation & $\begin{array}{l}4 \text { (Isoform } 2 \text { of Neurochondrin, Protein phosphatase 1E, Isoform Alpha CaMKII of Calcium/calmodulin-dependent } \\
\text { protein kinase type II subunit alpha, CaM kinase-like vesicle-associated protein) }\end{array}$ \\
\hline $2 \mathrm{E}$ & Synaptic vesicle proton gradient & $\begin{array}{l}3 \text { (V-type proton ATPase subunit E 1, V-type proton ATPase subunit d 1, V-type proton ATPase subunit B, brain } \\
\text { isoform) }\end{array}$ \\
\hline $2 \mathrm{~F}$ & Synaptic & 3 (Synaptic vesicle glycoprotein 2B, Dihydropyrimidinase-related protein 2, Isoform lb of Synapsin-1) \\
\hline 3 & Structural & $\begin{array}{l}15 \text { (Adenylyl cyclase-associated protein 1, Isoform } 2 \text { of Alpha-adducin, Isoform } 5 \text { of Dynamin-1, Beta-globin, } \\
\text { Tubulin alpha-4A chain, Tubulin alpha-1A chain, Profilin-1, Hemoglobin subunit beta-2, Isoform } 3 \text { of Dynamin-1, } \\
\text { Tubulin beta-2B chain, Tubulin beta-4 chain, Thy-1 membrane glycoprotein, Isoform } 2 \text { of Spectrin alpha chain, } \\
\text { brain, } 6.8 \mathrm{kDa} \text { mitochondrial proteolipid, cofilin-1-like) }\end{array}$ \\
\hline
\end{tabular}

\begin{tabular}{|c|c|c|}
\hline 4 & Protein synthesis & 1 (Isoform 3 of Ankyrin repeat and sterile alpha motif domain-containing protein 1B) \\
\hline 5 & Metabolism & $\begin{array}{l}13 \text { (Phosphoglycerate kinase 1, Cytochrome c oxidase subunit 7A2, mitochondrial, Transaldolase, } \\
\text { Thioredoxin-dependent peroxide reductase, mitochondrial, Phosphorylase, Isoform M1 of Pyruvate kinase } \\
\text { isozymes M1/M2, Creatine kinase U-type, mitochondrial, Cytochrome b-c1 complex subunit 2, mitochondrial, } \\
\text { Isoform } 1 \text { of Low molecular weight phosphotyrosine protein phosphatase, Fructose-bisphosphate aldolase A, } \\
\text { Isoform } 2 \text { of Obg-like ATPase 1, Serine/threonine-protein phosphatase, Cytochrome b-c1 complex subunit } 8 \text { ) }\end{array}$ \\
\hline 6 & Chaperone & 2 (Heat shock protein HSP 90-beta, Parkinson disease (Autosomal recessive, early onset) 7) \\
\hline 7 & Cell signaling & $\begin{array}{l}9 \text { (plasma membrane calcium ATPase 1, NEDD8, Isoform } 2 \text { of Serine/threonine-protein phosphatase 2B catalytic } \\
\text { subunit alpha isoform, Isoform } 2 \text { of 14-3-3 protein theta, 14-3-3 protein zeta/delta, 14-3-3 protein epsilon, 14-3-3 } \\
\text { protein gamma, Isoform } 2 \text { of Nck-associated protein 1, Gamma-enolase) }\end{array}$ \\
\hline
\end{tabular}

\begin{tabular}{|c|c|c|}
\hline 8 & Cell adhesion and migration & 1 (neurocan core protein-like) \\
\hline 9 & Vesicular trafficking and fusion & 2 (Clathrin heavy chain 1, AP-2 complex subunit alpha-2) \\
\hline
\end{tabular}

The classifications have been done manually based on Refseq and Uniprot annotations.

from promoters containing the Estrogen Receptor Element (ERE) (Figure 7D) in both presence and absence of estradiol. Luciferase assay also indicated that co-expression of WDR13 with c-JUN (Supplementary Figures 6A,B,D,E) resulted in repression of transcription from AP1 element containing promoter (Figure 7E; one way ANOVA; $p<0.05$ ). We therefore hypothesized that in the absence of $W d r 13$, any repression (competitive or non-competitive) over key genes caused due to its interaction with its partner(s) (Perissi et al., 2010), might be relieved, resulting in their upregulation leading to the observed phenotype.

\section{DISCUSSION}

The current work highlights the action of $W d r 13$ in the brain. We showed that WDR13 represses transcription from AP1 and ERE elements containing promoters, which harbor c-JUN and $\mathrm{ER} \alpha / \beta$ responsive elements respectively. Absence of $W d r 13$ led to de-regulated expression of multiple genes. Many of these include synaptic genes like $S y n 1, R a b 3 a, N r x n 2, C a m k 2 a$, etc. Interestingly, we showed that absence of $W d r 13$ caused mild anxiety and improved retention in MWM task, associated with increased spine density. 


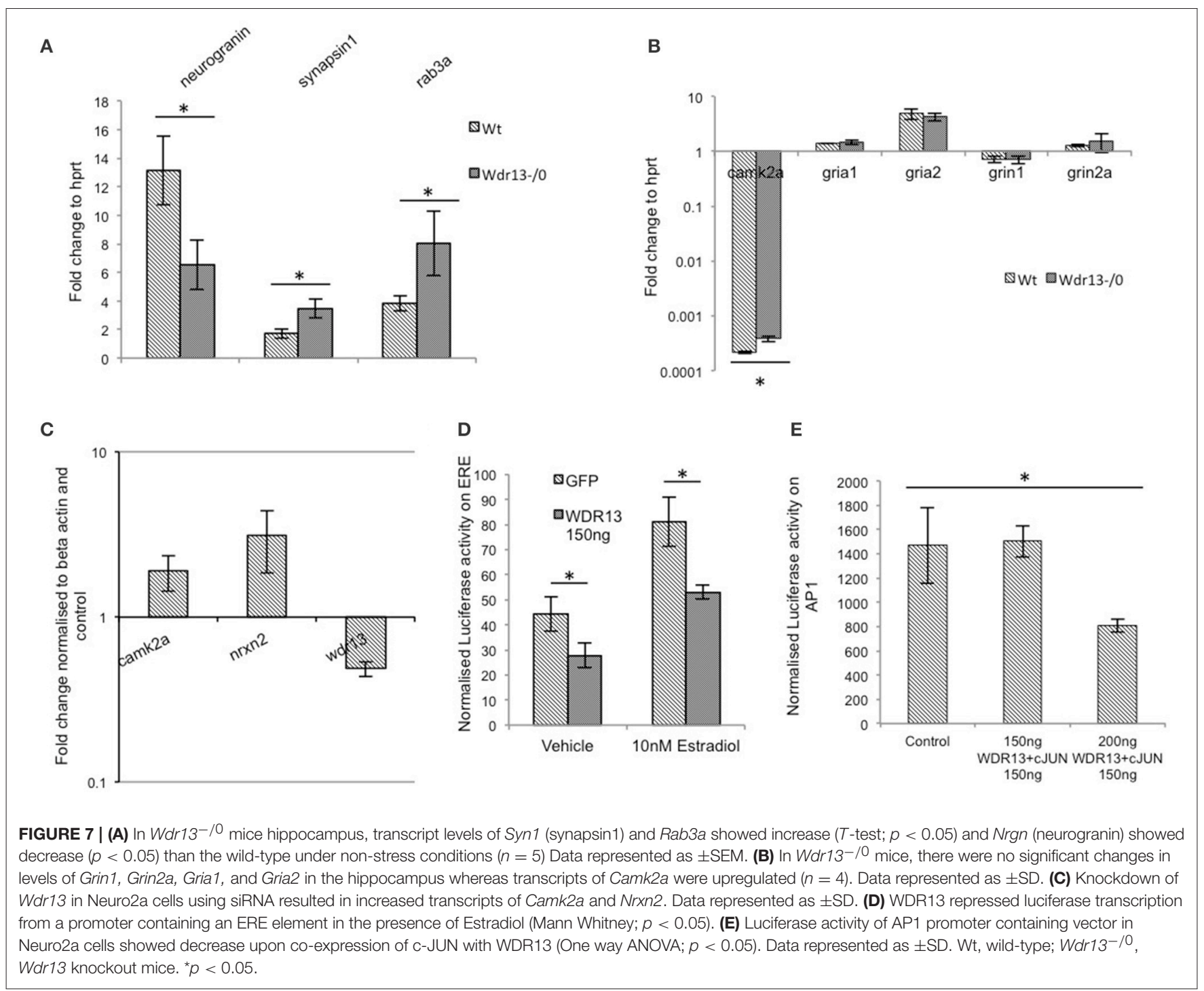

We selected the age window of 2-3 months of age to carry out all behavior experiments. There were no systemic changes in the $W d r 13^{-/ 0}$ mice at this age (Singh et al., 2012) and we did not find any changes in brain metabolism. Though we found increased glutamate metabolism at 10 months of age in mutant mice, we argued that this change was mostly neuronal, considering that there were no changes in concentration of $13 \mathrm{C}$ glutamate labeled from acetate- indicative of astroglial metabolism. The changes observed at 10 months in $W d r 13^{-/ 0}$ mice might have resulted from accumulating molecular changes in the brain due to the absence of $W d r 13$. Since de-regulation of glutamate can lead to changes in memory (McEntee and Crook, 1993; Gecz, 2010), anxiety (Bergink et al., 2004), depression (Sanacora et al., 2012), etc., it would be interesting to study the behavioral phenotype of $W d r 13^{-/ 0}$ mice at 10 months of age. Increase in glutamate in a chronic state can also lead to excitotoxicity (Foran and Trotti, 2009). Therefore, analysis of brain function and anatomy is important to shed light on the effect of genetic deletion of
Wdr13 in aged mice brain. A conditional knockout mouse with brain specific deletion of $W d r 13$ would be more suitable for this age dependent study since systemic metabolic effects because of the absence of this gene could be avoided.

Before analyzing differentially regulated genes, we asked if whether the proliferation of adult neuronal precursor cells was affected using BrDU labeling. Our results showed no significant difference in BrDU positive cells of DG and SVZ between $W d r 13^{-/ 0}$ and wild-type mice unlike pancreatic beta cells. This also indicated that the pathways affected in brain might be different from pancreas or other tissues.

We showed that the absence of $W d r 13$ resulted in upregulation of multiple synaptic proteins (16 out of 78 upregulated) in-vivo. We showed similar results in downregulation of Wdr13 in Neuro2a cell lines indicating that the changes occurred as a consequence of loss of the gene and not due to any systemic effects. The synaptic proteins found upregulated could be classified into AMPA cycling, 
Glutamate cycling, GABA metabolism, CAM kinase regulation, Synaptic vesicle proton gradient and synaptic vesicle cycling (Table 1). We observed notable upregulation in Camk2a, Syn1, and Rab3a levels in $W d r 13^{-/ 0}$ mice at transcript and protein levels. It is known that synapsins control the release of neurotransmitters such as glutamate and important for synaptic plasticity (Nichols et al., 1992; Jovanovic et al., 2000). Synapsins are involved in memory formation and consolidation process in drosophila and in aging-related memory impairment in mammals (Godenschwege et al., 2004; John et al., 2009). Similarly, RAB3A is important for synaptic transmission, learning and memory (Yang et al., 2007). CAMK2A belongs to the CaM-kinase II family of proteins-known for their significant role in synaptic plasticity, long term potentiation (LTP), and learning and memory (Soderling, 1993). Levels of Vesicular glutamate transporter 1 (VGLUT1) - an important molecule for excitatory synapse and for maintaining LTP (Balschun et al., 2010) was also found to be increased in $W d r 13^{-/ 0}$ mice. Upregulation was also recorded in the levels of 14-3-3 proteins in $W d r 13^{-/ 0}$ mice. 14-3-3 proteins are positive regulators of associative learning and memory (Qiao et al., 2014). An upregulation in dynamins and tubulins found in the $W d r 13^{-/ 0}$ mice could be important factors behind the increased spine density observed (Gray et al., 2005; Shirao and González-Billault, 2013). Since spine density has been related to learning and memory, upregulation of afore-mentioned proteins might be of significance regarding the observed phenotype. We also found upregulation of immediate early genes $A r c$ and $c$-Fos in $W d r 13^{-/ 0}$ mice when exposed to a novel environment as compared to wild-type mice. Arc has traditionally been associated with learning and memory, particularly long term spatial memory (Bramham et al., 2010). C-Fos has also been shown to be upregulated during learning trials (Alberini, 2009). It may be noted that no changes were found in the transcript levels of NMDA and AMPA receptor genes. However, considering that the levels of multiple synaptic proteins including important proteins like CAMK2A and immediate early genes like $A r c$, were found to be upregulated, an increased LTP might be expected to be associated with the phenotype of better spatial memory in $W d r 13^{-/ 0}$ mice. These findings may be corroborated with the help of further experiments particularly electrophysiology. Thus, taken together, increase in levels of above mentioned synaptic proteins and increased synaptic activity as measured by Arc and $c$-Fos, might be few of the key factors responsible for better performance in spatial memory task of MWM by $W d r 13^{-/ 0}$ mice.

Interestingly, many of the synaptic proteins along with Clathrin, AP-2, and Dynamin found up-regulated in $W d r 13^{-/ 0}$ mice are also known to be important for synaptic vesicle recycling. Synaptic vesicle recycling is essential for synaptic plasticity, memory, and cognitive ability, and any deleterious changes in it lead to mental retardation, schizophrenia, and defects in spatial memory (Murthy and De Camilli, 2003; Glyvuk et al., 2010; Cottrell et al., 2013). Synaptic recycling affects synaptic transmission (Casillas-Espinosa et al., 2012) and consequently memory through LTP (Hölscher, 1999). In this context it would be interesting to investigate synaptic recycling in these mutant mice.

Though $W d r 13^{-/ 0}$ mice showed better spatial memory, they didn't show any differences in spatial learning as assessed using MWM than that of the wild-type mice. Previous reports show that disruption of a gene can affect memory without significantly changing learning ability (Maguschak and Ressler, 2008; Tsai et al., 2012) though the molecular reasons are not clearly understood.

$W d r 13^{-/ 0}$ mice also showed decreased exploration of central area of OFT and active avoidance of novel object but failed to show any significant difference in EPM, particularly in CD1 background. It is possible that the response of the mutant mice was directed specifically against novel environment (Bailey and Crawley, 2009) and therefore differences were observed in OFT and NOR. Since the mutant mice also traversed significantly more distance, it explored EPM as much as the wild-type mice leading to no observable differences in CD1 background. However, it is to be noted that mutant mice in $\mathrm{C} 57 \mathrm{Bl} / 6 \mathrm{~J}$ background showed a trend of increased visit to closed arm of EPM, and therefore, it is possible that this phenotype of mild novelty-associated anxiety was affected by the genetic background (CD1).

In our analysis, we found decreased levels of Neurogranin $(\mathrm{Nrgn})$ at protein and transcript levels in $W d r 13^{-/ 0}$ mice. Neurogranin is a brain-specific calmodulin-binding protein expressed particularly in dendritic spines. $\mathrm{Nrgn}^{-/-}$mice exhibit characteristics of anxiety (Miyakawa et al., 2001). Similarly, it has been shown that overexpression of Camk2a leads to increased anxiety in mice (Hasegawa et al., 2009).

It is known through previous studies carried out in our lab that WDR13 interacts with c-JUN, Estrogen receptors ER $\alpha / \beta$ and HDACs (V. P. Singh and Shalu Singh, personal communication). Consistent with our previous findings, we show that WDR13 represses transcription from promoter containing ERE $(\mathrm{ER} \alpha / \beta$ responsive) and AP1 (c-JUN responsive) elements. The action leading to the observed phenotype and deregulation of the multiple afore-mentioned genes in $W d r 13^{-/ 0}$ mice might have been attained by relieving of competitive repression (Perissi et al., 2010) induced by WDR13 on downstream targets of c-JUN and $\mathrm{ER} \alpha / \beta$-both shown to be positive regulators of learning and memory genes. Learning trials are known to increase cJun levels which affect learning positively by altering the expression of downstream genes (Alberini, 2009). While estrogen aids synaptic transmission and plasticity by positively regulating synaptic genes (Foy et al., 2010), activation of Estrogen receptors like $\operatorname{ER} \beta$ has also been shown to improve memory (Liu et al., 2008). Further, estrogen induces synaptic protein CAMK2A activity invivo (Sawai et al., 2002). Additionally, administration of estradiol increases transcription of Syn1 (Pan et al., 2010). Syn1 has also been reported to contain an ERE element upstream (Bourdeau et al., 2004) indicating that the action of estrogen on its transcription is guided through Estrogen receptors. Interestingly, in our analysis we have found both Camk2a and Syn1 to be upregulated in $W d r 13^{-/ 0}$ mice.

Multiple genes that affect memory and learning have been reported in previous studies. Modulation of expression of a 
number of them had resulted in better learning and memory. These genes affect different processes like excitatory synaptic transmission ( $\mathrm{Nr} 2 b, \mathrm{Cdk5}, \mathrm{p} 25, \mathrm{Hgf}$ etc.), inhibitory synaptic transmission (GABA receptor, Grpr, $P k r$ etc.), pre-synaptic function (H-ras, Ncx2, Cbl-b, etc.), transcriptional regulation (CREB, CamkIV, Gcn2, Calcineurin, etc.), miRNA biogenesis (Dicer1), epigenetic regulation (Hdac2) etc. (Lee, 2014). Our results show that absence of $W d r 13$ in 2 months old mice leads to better spatial memory associated with upregulation of multiple synaptic proteins. While it is exciting to find a molecule, manipulation of which may enhance memory, longterm implications of removal of this gene needs to be studied. As mentioned earlier increased glutamate can lead to excitotoxicity and neuronal death and hence aged mice lacking $W d r 13$ should be analyzed. Also, the persistent increase in synaptic proteins has been associated with schizophrenia (Li et al., 2015). Hence, it should be investigated whether absence of $W d r 13$ leads to hallucinogenic or schizophrenia like effect in mice with increasing age.

\section{AUTHOR CONTRIBUTIONS}

SM designed and executed the experiments and drafted the manuscript. GS executed with SM proteomics experiments. VT with SM executed NMR experiments. BL helped in animal breeding, maintenance, and genotyping. ST supervised the proteomics experiment providing inputs and helping in design, execute and in acquisition of the results for the experiment. SK gave inputs, aided in interpreting the data, revised the draft manuscript and finalized it.

\section{ACKNOWLEDGMENTS}

We thank Dr. Archana B. Siva and Dr. T. Ramakrishna Murthy for proof reading and suggestions. We thank colleagues at Brain and Behavioral Facility at CCMB for the animal experiments. We thank CSIR and CCMB for funding.

\section{SUPPLEMENTARY MATERIAL}

The Supplementary Material for this article can be found online at: http://journal.frontiersin.org/article/10.3389/fnmol. 2016.00073

Supplementary Figure 1 | RNA in situ hybridization of Wdr13 in the brain. (A) RISH using antisense Wdr13 probe showed localization of it's transcript in

\section{REFERENCES}

Alberini, C. M. (2009). Transcription factors in long-term memory and synaptic plasticity. Physiol. Rev. 89, 121-145. doi: 10.1152/physrev.00017.2008

Antunes, M., and Biala, G. (2012). The novel object recognition memory: neurobiology, test procedure, and its modifications. Cogn. Process. 13, 93-110. doi: 10.1007/s10339-011-0430-z

Bailey, K. R., and Crawley, J. N. (2009). "Anxiety-related behaviors in mice," in Methods of Behavior Analysis in Neuroscience, 2nd Edn., Chapter 5, ed J. J. Buccafusco (Boca Raton, FL: CRC Press/Taylor \& Francis).
Hippocampal CA1, CA2, CA3 region, and Dentate Gyrus, and in Cortex. The left panel depicts antisense probe and right panel depicts sense probe. Scale $1 \mathrm{~mm}$ (B) Antisense Wdr13 probing (top) of a sagittal section of mouse brain showing significant hybridization in Cerebellum, Hippocampus, and Cortex. Scale $1 \mathrm{~mm}$. (C) A coronal section of cortex hybridized with anti-sense Wdr13 probe. Scale $200 \mu \mathrm{m}$.

Supplementary Figure 2 | Histological staining of brain sections from Wdr13 $-/ 0$ and wild-type mice showed no significant differences $(n=3)$. (A) Nissl staining of a coronal section of brain showing the hippocampus. Wild-type is shown on left and $W d r 13^{-/ 0}$ on right. (B) Nissl staining of sagittal section of brain. Wild-type is shown in top and $W d r 13^{-/ 0}$ in bottom panel. (C) H\&E staining of a coronal section of brain. Wild-type on left and $W d r 13^{-/ 0}$ on right. (D) H\&E staining of sagittal section of brain. Wild-type on top and Wdr13-/0 bottom panel. Scale $1 \mathrm{~mm}$.

Supplementary Figure 3 | Additional dataset: Behavioral analysis of Wdr13 ${ }^{-/ 0}$ and wild-type mice in CD1 background (Cohort 1). (A) Open field test. Wdr $13^{-/ 0}$ mice showed marginally ( $T$-test; $p=0.07$ ) decreased exploration time in the central area of the open field as compared to the wild-types. (B) Novel object recognition test. $W d r 13^{-/ 0}$ mice showed a trend (T-test; $p=0.06$ ) of decreased exploration of novel object than the familiar object $(n=5)$. (C) Elevated plus maze test. There were no significant differences ( $T$-test; $p>0.05$ ) between Wdr13-/0 and wild-type mice in total time spent in closed or open arms $(n=5)$. (D) Morris water maze test. Wdr13-/0 mice spent significantly more time [ANOVA, $F_{(1,56)}=5.44 ; p<0.05$ ] in the target quadrant during extinction trials as compared to the wild-type mice $(n=5)$. Data represented as \pm SEM. Wt, wild-type; Wdr13-10, Wdr13 knockout mice. $* p<0.05$.

Supplementary Figure 4 | Tracking adult neuronal proliferation in Wdr13-10 and wild-type mice using BrDU labeling. (A) Representative images of fluorescent labeling for anti-BrDU in wild-type and $W d r 13^{-/ 0}$ Dentate Gyrus (DG). ( $\left.\mathbf{A}^{\prime}\right)$ There was no significant difference ( $T$-test; $\left.p>0.05\right)$ in the number of BrDU labeled cells from the DG of hippocampus. (B) Representative images of Dab staining for anti-BrDU labeling in wild-type and Wdr13-/0 Sub Ventricular Zone (SVZ). (B') There was no significant difference ( $T$-test; $p>0.05$ ) in the number of BrDU labeled cells from SVZ of Wdr13-10 and wild-type mice. (C) There were no significant differences in number of BrDU positive cells in hippocampal DG and in (D). SVZ of $W d r 13^{-/ 0}$ mice as compared to the wild-type mice after performing learning task in Morris water maze. Data represented as \pm SEM. Wt, wild-type; Wdr13-10, Wdr13 knockout mice.

Supplementary Figure 5 | Real time analysis of hippocampus from Wdr13 $-/ 0$ and wild-type mice which were exposed to a novel environment revealed increased transcripts of $c$-Fos and Arc in Wdr13-/0

hippocampus. However, there was no significant difference $(T$-test; $p>0.05)$ in transcript levels of Bdnf $(n=4)$. Data is represented $\pm S D$. Wt, wild-type; Wdr13 -10 , Wdr13 knockout mice.

Supplementary Figure 6 | Western analysis. (A) Representative blot of WDR13 overexpression and knockdown (from left) in Neuro2a cells. (B) Relative quantification of WDR13 overexpression (Mann Whitney; $p<0.05$ ) and knockdown (Mann Whitney; $p<0.05$ ). (C) Percent relative expression (compared to controls) for WDR13 knockdown and overexpression. (D) Representative blot and $\mathbf{( E )}$ relative quantification (triplicates) of C-JUN overexpression (Mann Whitney; $p<0.05)$ in Neuro2a cell line. Data is represented \pm SD. in hippocampal long-term potentiation and spatial reversal learning. Cereb. Cortex 20, 684-693. doi: 10.1093/cercor/bhp133

Barnhart, C. D., Yang, D., and Lein, P. J. (2015). Using the Morris water maze to assess spatial learning and memory in weanling mice. PLOS ONE 10:e0124521. doi: 10.1371/journal.pone.0124521

Becker, C., Zeau, B., Rivat, C., Blugeot, A., Hamon, M., and Benoliel, J.-J. (2008). Repeated social defeat-induced depression-like behavioral and biological alterations in rats: involvement of cholecystokinin. Mol. Psychiatry 13, 1079-1092. doi: 10.1038/sj.mp.4002097 
Bergink, V., van Megen, H. J. G. M., and Westenberg, H. G. M. (2004). Glutamate and anxiety. Eur. Neuropsychopharmacol. 14, 175-183. doi: 10.1016/S0924977X(03)00100-7

Bingham, E. M., Hopkins, D., Smith, D., Pernet, A., Hallett, W., Reed, L., et al. (2002). The role of insulin in human brain glucose metabolism: an 18fluorodeoxyglucose positron emission tomography study. Diabetes 51, 3384-3390. doi: $10.2337 /$ diabetes.51.12.3384

Bourdeau, V., Deschênes, J., Métivier, R., Nagai, Y., Nguyen, D., Bretschneider, N., et al. (2004). Genome-wide identification of high-affinity estrogen response elements in human and mouse. Mol. Endocrinol. 18, 1411-1427. doi: 10.1210/me.2003-0441

Bramham, C. R., Alme, M. N., Bittins, M., Kuipers, S. D., Nair, R. R., Pai, B., et al. (2010). The Arc of synaptic memory. Exp. Brain Res. 200, 125-140. doi: 10.1007/s00221-009-1959-2

Christmas, A., and Maxwell, D. (1970). A comparison of the effects of some benzodiazepines and other drugs on aggressive and exploratory behaviour in mice and rats. Neuropharmacology 9, 17-29. doi: 10.1016/0028-3908(70)9 0044-4

Can, A., Dao, D. T., Arad, M., Terrillion, C. E., Piantadosi, S. C., and Gould, T. D. (2012). The mouse forced swim test. J. Vis. Exp. 59:e3638. doi: 10.3791/3638

Casillas-Espinosa, P. M., Powell, K. L., and O’Brien, T. J. (2012). Regulators of synaptic transmission: roles in the pathogenesis and treatment of epilepsy. Epilepsia 53(Suppl. 9), 41-58. doi: 10.1111/epi.12034

Chakravarty, S., Maitra, S., Reddy, R. G., Das, T., Jhelum, P., Kootar, S., et al. (2015). A novel natural product inspired scaffold with robust neurotrophic, neurogenic and neuroprotective action. Sci. Rep. 5:14134. doi: 10.1038/srep14134

Clark, R. E., Broadbent, N. J., and Squire, L. R. (2007). The hippocampus and spatial memory: findings with a novel modification of the water maze. $J$. Neurosci. 27, 6647-6654. doi: 10.1523/JNEUROSCI.0913-07.2007

Cottrell, J. R., Levenson, J. M., Kim, S. H., Gibson, H. E., Richardson, K. A., Sivula, M., et al. (2013). Working memory impairment in calcineurin knock-out mice is associated with alterations in synaptic vesicle cycling and disruption of highfrequency synaptic and network activity in prefrontal cortex. J. Neurosci. 33, 10938-10949. doi: 10.1523/JNEUROSCI.5362-12.2013

Crawley, J. N. (2006). What's Wrong with My Mouse?: Behavioral Phenotyping of Transgenic and Knockout Mice, 2nd Edn. Hoboken, NJ: John Wiley \& Sons, Inc.

D'Agata, V., Schreurs, B. G., Pascale, A., Zohar, O., and Cavallaro, S. (2003). Down regulation of cerebellar memory related gene-1 following classical conditioning. Genes. Brain. Behav. 2, 231-237. doi: 10.1034/j.1601-183X.2003.00029.x

Deng, W., Aimone, J. B., and Gage, F. H. (2010). New neurons and new memories: how does adult hippocampal neurogenesis affect learning and memory? Nat. Rev. Neurosci. 11, 339-350. doi: 10.1038/nrn2822

El-Hattab, A. W., Bournat, J., Eng, P. A., Wu, J. B. S., Walker, B. A., Stankiewicz, P., et al. (2011). Microduplication of Xp11.23p11.3 with effects on cognition, behavior, and craniofacial development. Clin. Genet. 79, 531-538. doi: 10.1111/j.1399-0004.2010.01496.x

Fischer, A. H., Jacobson, K. A., Rose, J., and Zeller, R. (2008). Hematoxylin and eosin staining of tissue cell sections. CSH Protoc. 2008:pdb.prot4986. doi: $10.1101 /$ pdb.prot 4986

Foran, E., and Trotti, D. (2009). Glutamate transporters and the excitotoxic path to motor neuron degeneration in amyotrophic lateral sclerosis. Antioxid. Redox Signal. 11, 1587-1602. doi: 10.1089/ars.2009.2444

Foy, M. R., Baudry, M., Akopian, G. K., and Thompson, R. F. (2010). Regulation of hippocampal synaptic plasticity by estrogen and progesterone. Vitam. Horm. 82, 219-239. doi: $10.1016 / \mathrm{S} 0083-6729(10) 82012-6$

Gecz, J. (2010). Glutamate receptors and learning and memory. Nat. Genet. 42, 925-926. doi: 10.1038/ng1110-925

Glyvuk, N., Tsytsyura, Y., Geumann, C., D'Hooge, R., Hüve, J., Kratzke, M., et al. (2010). AP-1/sigmalB-adaptin mediates endosomal synaptic vesicle recycling, learning and memory. EMBO J. 29, 1318-1330. doi: 10.1038/emboj. 2010.15

Godenschwege, T. A., Reisch, D., Diegelmann, S., Eberle, K., Funk, N., Heisenberg, M., et al. (2004). Flies lacking all synapsins are unexpectedly healthy but are impaired in complex behaviour. Eur. J. Neurosci. 20, 611-622. doi: 10.1111/j.1460-9568.2004.03527.x

Gould, E., Beylin, A., Tanapat, P., Reeves, A., and Shors, T. J. (1999). Learning enhances adult neurogenesis in the hippocampal formation. Nat. Neurosci. 2, 260-265. doi: 10.1038/6365
Gray, N. W., Kruchten, A. E., Chen, J., and McNiven, M. A. (2005). A dynamin3 spliced variant modulates the actin/cortactin-dependent morphogenesis of dendritic spines. J. Cell Sci. 118, 1279-1290. doi: 10.1242/jcs.01711

Hall, C. S. (1934). Emotional behavior in the rat. I. Defecation and urination as measures of individual differences in emotionality. J. Comp. Psychol. 18, 385-403. doi: $10.1037 / \mathrm{h} 0071444$

Hasegawa, S., Furuichi, T., Yoshida, T., Endoh, K., Kato, K., Sado, M., et al. (2009). Transgenic up-regulation of alpha-CaMKII in forebrain leads to increased anxiety-like behaviors and aggression. Mol. Brain 2:6. doi: 10.1186/1756-6 606-2-6

Hölscher, C. (1999). Synaptic plasticity and learning and memory: LTP and beyond. J. Neurosci. Res. 58, 62-75. doi: 10.1002/(SICI)10974547(19991001)58:1<62::AID-JNR7>3.3.CO;2-7

Inostroza, M., Cid, E., Brotons-Mas, J., Gal, B., Aivar, P., Uzcateg, Y. G., et al. (2011). Hippocampal-Dependent spatial memory in the water maze is preserved in an experimental model of temporal lobe epilepsy in rats. PLoS ONE 6:e22372. doi: 10.1371/journal.pone.0022372

John, J. P. P., Sunyer, B., Höger, H., Pollak, A., and Lubec, G. (2009). Hippocampal synapsin isoform levels are linked to spatial memory enhancement by SGS742. Hippocampus 19, 731-738. doi: 10.1002/hipo.20553

Jovanovic, J. N., Czernik, A. J., Fienberg, A. A., Greengard, P., and Sihra, T. S. (2000). Synapsins as mediators of BDNF-enhanced neurotransmitter release. Nat. Neurosci. 3, 323-329. doi: 10.1038/73888

Lee, Y.-S. (2014). Genes and signaling pathways involved in memory enhancement in mutant mice. Mol. Brain 7:43. doi: 10.1186/1756-6606-7-43

Lein, E. S., Hawrylycz, M. J., Ao, N., Ayres, M., Bensinger, A., Bernard, A., et al. (2007). Genome-wide atlas of gene expression in the adult mouse brain. Nature $445,168-176$. doi: 10.1038 /nature 05453

Leuner, B., Falduto, J., and Shors, T. J. (2003). Associative memory formation increases the observation of dendritic spines in the hippocampus. J. Neurosci. $23,659-665$.

Li, W., Ghose, S., Gleason, K., Begovic, A., Perez, J., Bartko, J., et al. (2015). Synaptic proteins in the hippocampus indicative of increased neuronal activity in CA3 in Schizophrenia. Am. J. Psychiatry 172, 373-382. doi: 10.1176/appi.ajp.2014.14010123

Liu, F., Day, M., Muñiz, L. C., Bitran, D., Arias, R., Revilla-Sanchez, R., et al. (2008). Activation of estrogen receptor-beta regulates hippocampal synaptic plasticity and improves memory. Nat. Neurosci. 11, 334-343. doi: 10.1038/nn2057

Maei, H. R., Zaslavsky, K., Teixeira, C. M., and Frankland, P. W. (2009). What is the most sensitive measure of water maze probe test performance? Front. Integr. Neurosci. 3:4. doi: 10.3389/neuro.07.004.2009

Maguschak, K. A., and Ressler, K. J. (2008). Beta-catenin is required for memory consolidation. Nat. Neurosci. 11, 1319-1326. doi: 10.1038/nn.2198

McEntee, W. J., and Crook, T. H. (1993). Glutamate: its role in learning, memory, and the aging brain. Psychopharmacology (Berl.) 111, 391-401. doi: $10.1007 / \mathrm{BF} 02253527$

Minett, M., Nassar, M., Clark, A., Passmore, G., Dickenson, A., Wang, F., et al. (2012). Distinct Nav1.7-dependent pain sensations require different sets of sensory and sympathetic neurons. Nat. Commun. 3, 791-799. doi: 10.1038/ncomms1795

Miyakawa, T., Yared, E., Pak, J. H., Huang, F. L., Huang, K. P., and Crawley, J. N. (2001). Neurogranin null mutant mice display performance deficits on spatial learning tasks with anxiety related components. Hippocampus 11, 763-775. doi: 10.1002/hipo.1092

Morris, R. G. M. (1981). Spatial localization does not require the presence of local cues. Learn. Motiv. 12, 239-260. doi: 10.1016/0023-9690(81)90020-5

Moser, M. B., Trommald, M., and Andersen, P. (1994). An increase in dendritic spine density on hippocampal CA1 pyramidal cells following spatial learning in adult rats suggests the formation of new synapses. Proc. Natl. Acad. Sci. U.S.A. $91,12673-12675$

Murthy, V. N., and De Camilli, P. (2003). Cell biology of the presynaptic terminal. Annu. Rev. Neurosci. 26, 701-728. doi: 10.1146/annurev.neuro.26.041002. 131445

Nichols, R. A., Chilcote, T. J., Czernik, A. J., and Greengard, P. (1992). Synapsin I regulates glutamate release from rat brain synaptosomes. J. Neurochem. 58, 783-785.

Nissl, F. (1894). Ueber eine neue untersuchungsmethode des centralorgans zur feststellung der localisation der nervenzellen. Neurol. Cent. 13, 507-508. 
Orlowski, D., and Bjarkam, C. R. (2012). A simple reproducible and time saving method of semi-automatic dendrite spine density estimation compared to manual spine counting. J. Neurosci. Methods 208, 128-133. doi: 10.1016/j.jneumeth.2012.05.009

Pan, M., Li, Z., Yeung, V., and Xu, R.-J. (2010). Dietary supplementation of soy germ phytoestrogens or estradiol improves spatial memory performance and increases gene expression of BDNF, TrkB receptor and synaptic factors in ovariectomized rats. Nutr. Metab. 7:75. doi: 10.1186/17437075-7-75

Patel, A. B., Rothman, D. L., Cline, G. W., and Behar, K. L. (2001). Glutamine is the major precursor for GABA synthesis in rat neocortex in vivo following acute GABA-transaminase inhibition. Brain Res. 919, 207-220. doi: 10.1016/S00068993(01)03015-3

Perissi, V., Jepsen, K., Glass, C. K., and Rosenfeld, M. G. (2010). Deconstructing repression: evolving models of co-repressor action. Nat. Rev. Genet. 11, 109-123. doi: 10.1038/nrg2736

Porsolt, R. D., Bertin, A., and Jalfre, M. (1977). Behavioral despair in mice: a primary screening test for antidepressants. Arch. Int. Pharmacodyn. Thér. 229, 327-336. doi: 10.1196/annals.1317.038

Price, M., Lang, M. G., Frank, A. T., Goetting-Minesky, M. P., Patel, S. P., Silviera, M. L., et al. (2003). Seven cDNAs enriched following hippocampal lesion: possible roles in neuronal responses to injury. Brain Res. Mol. Brain Res. 117, 58-67. doi: 10.1016/S0169-328X(03)00285-7

Qiao, H., Foote, M., Graham, K., Wu, Y., and Zhou, Y. (2014). 14-3-3 Proteins are required for hippocampal long-term potentiation and associative learning and memory. J. Neurosci. 34, 4801-4808. doi: 10.1523/JNEUROSCI.439313.2014

Ramos, J. M. (2000). Long-term spatial memory in rats with hippocampal lesions. Eur. J. Neurosci. 12, 3375-3384. doi: 10.1046/j.1460-9568.2000.00206.x

Restivo, L., Vetere, G., Bontempi, B., and Ammassari-Teule, M. (2009). The formation of recent and remote memory is associated with time-dependent formation of dendritic spines in the hippocampus and anterior cingulate cortex. J. Neurosci. 29, 8206-8214. doi: 10.1523/JNEUROSCI.0966-09.2009

Sambrook, J., and Russell, D. W. (2001). Molecular Cloning: A Laboratory Manual. Cold Spring, NY: Cold Spring Harbor Laboratory Press. Available at: http://books.google.com/books?id=YTxKwWUiBeUC\&printsec=frontcover $\backslash$ npapers2://publication/uuid/BBBF5563-6091-40C6-8B14-06ACC3392EBB

Sanacora, G., Treccani, G., and Popoli, M. (2012). Towards a glutamate hypothesis of depression: an emerging frontier of neuropsychopharmacology for mood disorders. Neuropharmacology 62, 63-77. doi: 10.1016/j.neuropharm.2011. 07.036

Sawai, T., Bernier, F., Fukushima, T., Hashimoto, T., Ogura, H., and Nishizawa, Y. (2002). Estrogen induces a rapid increase of calcium-calmodulin-dependent protein kinase II activity in the hippocampus. Brain Res. 950, 308-311. doi: 10.1016/S0006-8993(02)03186-4

Segal, M. (2005). Dendritic spines and long-term plasticity. Nat. Rev. Neurosci. 6, 277-284. doi: 10.1038/nrn1649

Shameem, M., and Patel, A. B. (2012). Glutamatergic and GABAergic metabolism in mouse brain under chronic nicotine exposure: implications for addiction. PLOS ONE 7:e41824. doi: 10.1371/journal.pone. 0041824

Shirao, T., and González-Billault, C. (2013). Actin filaments and microtubules in dendritic spines. J. Neurochem. 126, 155-164. doi: 10.1111/jnc.12313

Singh, B. N., Suresh, A., UmaPrasad, G., Subramanian, S., Sultana, M., Goel, S., et al. (2003). A highly conserved human gene encoding a novel member of WDrepeat family of proteins (WDR13). Genomics 81, 315-328. doi: 10.1016/S08887543(02)00036-8
Singh, V. P., Alex, J. L., Lakshmi, B. J., Sailasree, S. P., Raj, T. A., and Kumar, S. (2015a). Role of mouse Wdr13 in placental growth; a genetic evidence for lifetime body weight determination by placenta during development. Sci. Rep. 5:13371. doi: 10.1038/srep13371

Singh, V. P., Gurunathan, C., Singh, S., Singh, B., Lakshmi, B. J., Mishra, A. P., et al. (2015b). Genetic deletion of Wdr13 improves the metabolic phenotype of Lepr $(\mathrm{db} / \mathrm{db})$ mice by modulating AP1 and PPAR $\gamma$ target genes. Diabetologia 58, 384-392. doi: 10.1007/s00125-014-3438-y

Singh, V. P., Lakshmi, B. J., Singh, S., Shah, V., Goel, S., Sarathi, D. P., et al. (2012). Lack of Wdr13 gene in mice leads to enhanced pancreatic beta cell proliferation, hyperinsulinemia and mild obesity. PLoS ONE 7:e38685. doi: 10.1371/journal.pone.0038685

Soderling, T. R. (1993). Calcium/calmodulin-dependent protein kinase II: role in learning and memory. Mol. Cell. Biochem. 127-128, 93-101.

Suresh, A., Shah, V., Rani, D. S., Singh, B. N., Prasad, G. U., Subramanian, S., et al. (2005). A mouse gene encoding a novel member of the WD family of proteins is highly conserved and predominantly expressed in the testis (Wdr13). Mol. Reprod. Dev. 72, 299-310. doi: 10.1002/mrd. 20362

Terry, A. V. Jr. (2009). "Spatial navigation (water maze) tasks," in Methods of Behavior Analysis in Neuroscience, 2nd Edn., Chapter 13, ed J. J. Buccafusco (Boca Raton, FL: CRC Press/Taylor \& Francis).

Tiwari, V., and Patel, A. B. (2012). Impaired glutamatergic and GABAergic function at early age in APPswe-PS1dE9 mice: implications for preclinical diagnosis of Alzheimer's disease 1. J. Alzheimers Dis. 20, 11906. doi: 10.3233/JAD-2011-111502

Tsai, L. C. L., Chan, G. C. K., Nangle, S. N., Shimizu-Albergine, M., Jones, G. L., Storm, D. R., et al. (2012). Inactivation of Pde8b enhances memory, motor performance, and protects against age-induced motor coordination decay. Genes Brain Behav. 11, 837-847. doi: 10.1111/j.1601-183X.2012.00836.x

Vorhees, C. V., and Williams, M. T. (2006). Morris water maze: procedures for assessing spatial and related forms of learning and memory. Nat. Protoc. 1, 848-858. doi: 10.1038/nprot.2006.116

Waniewski, R. A., and Martin, D. L. (1998). Preferential utilization of acetate by astrocytes is attributable to transport. J. Neurosci. 18, 5225-5233.

Yang, S., Farias, M., Kapfhamer, D., Tobias, J., Grant, G., Abel, T., et al. (2007). Biochemical, molecular and behavioral phenotypes of Rab3A mutations in the mouse. Genes Brain Behav. 6, 77-96. doi: 10.1111/j.1601-183X.2006.00235.x

Yau, P. L., Castro, M. G., Tagani, A., Tsui, W. H., and Convit, A. (2012). Obesity and metabolic syndrome and functional and structural brain impairments in adolescence. Pediatrics 130, e856-e864. doi: 10.1542/peds.2012-0324

Conflict of Interest Statement: The authors declare that the research was conducted in the absence of any commercial or financial relationships that could be construed as a potential conflict of interest.

The reviewer SB and handling Editor declared their shared affiliation, and the handling Editor states that the process nevertheless met the standards of a fair and objective review.

Copyright (c) 2016 Mitra, Sameer Kumar, Tiwari, Lakshmi, Thakur and Kumar. This is an open-access article distributed under the terms of the Creative Commons Attribution License (CC BY). The use, distribution or reproduction in other forums is permitted, provided the original author(s) or licensor are credited and that the original publication in this journal is cited, in accordance with accepted academic practice. No use, distribution or reproduction is permitted which does not comply with these terms. 